\title{
External Thermal Insulation Composite Systems: Critical Parameters for Surface Hygrothermal Behaviour
}

\author{
Eva Barreira and Vasco P. de Freitas \\ Laboratory of Building Physics (LFC), Civil Engineering Department (DEC), Faculty of Engineering-University of Porto (FE/UP), \\ Rua Dr. Roberto Frias, 4200-465 Porto, Portugal
}

Correspondence should be addressed to Eva Barreira; barreira@fe.up.pt

Received 13 May 2013; Accepted 4 November 2013; Published 5 February 2014

Academic Editor: Markku Leskela

Copyright (C) 2014 E. Barreira and V. P. de Freitas. This is an open access article distributed under the Creative Commons Attribution License, which permits unrestricted use, distribution, and reproduction in any medium, provided the original work is properly cited.

\begin{abstract}
External Thermal Insulation Composite Systems (ETICS) are often used in Europe. Despite its thermal advantages, low cost, and ease of application, this system has serious problems of biological growth causing the cladding defacement. Recent studies pointed that biological growth is due to high values of surface moisture content, which mostly results from the combined effect of exterior surface condensation, wind-driven rain, and drying process. Based on numerical simulation, this paper points the most critical parameters involved in hygrothermal behaviour of ETICS, considering the influence of thermal and hygric properties of the external rendering, the effect of the characteristics of the façade, and the consequences of the exterior and interior climate on exterior surface condensation, wind-driven rain, and drying process. The model used was previously validated by comparison with the results of an "in situ" campaign. The results of the sensitivity analyses show that relative humidity and temperature of the exterior air, atmospheric radiation, and emissivity of the exterior rendering are the parameters that most influence exterior surface condensation. Winddriven rain depends mostly on horizontal rain, building's height, wind velocity, and orientation. The drying capacity is influenced by short-wave absorbance, incident solar radiation, and orientation.
\end{abstract}

\section{Introduction}

External Thermal Insulation Composite Systems (ETICS) are often used in Europe since the 70's, both in new buildings and in retrofitting. The popularity of this technology grew due to its advantages regarding other techniques of insulation. ETICS guarantees the reduction of the thermal bridges and greater thermal comfort due to the higher interior thermal inertia, providing a finished appearance similar to the traditional rendering. From the construction point of view, ETICS allows thinner exterior walls and increases the facades' durability. To the pointed advantages, three very relevant aspects in the construction industry must be added: low cost, ease of application, and possibility to be installed without disturbing the building's dwellers, which is particularly important in refurbishment.

However, past applications of ETICS have revealed some problems, particularly low impact resistance and the cladding defacement due to biological growth. The scientific community has performed various studies to fully characterise these systems, to measure the properties of its components, to identify the main problems, and, in some cases, to develop solutions [1-6].

One of the problems not yet solved is the cladding defacement due to biological growth. Studies already performed in this field pointed high values of surface moisture content as the cause of biological growth. External surface moisture results from the combined effect of four parameters: surface condensation, wind-driven rain, drying process, and properties of the exterior layer $[3,5,7-15]$.

Although no changes occur in the thermal and mechanical performance of the system, biological defacement has an enormous aesthetic impact, which gathers the building's dwellers disapproval and restricts the full implementation of this technology.

\section{Main Advantages and Pathologies of ETICS}

According to ETAG 004 [16], ETICS are systems comprising prefabricated insulation panels, bonded and/or mechanically 


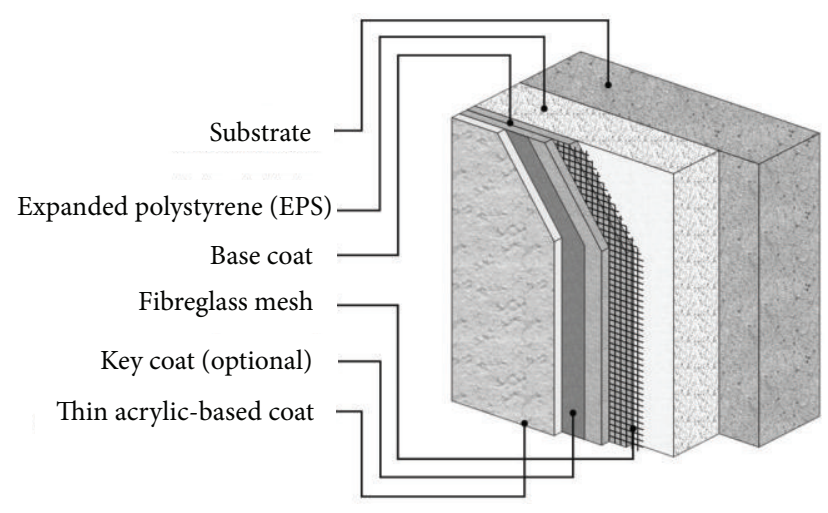

FIgURE 1: Schematic example of ETICS available in the Portuguese market [4].
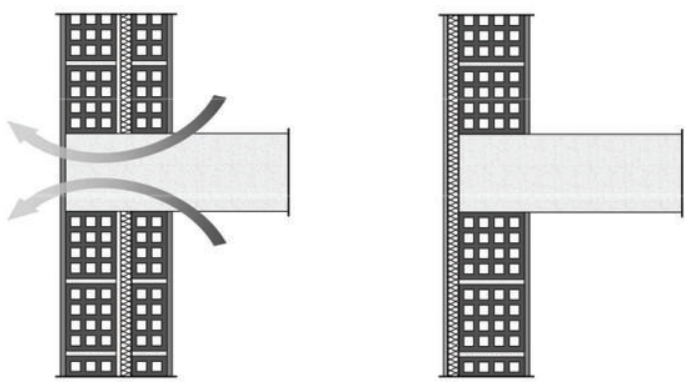

FIGURE 2: Reduction of heat losses due to the continued thermal insulation [4].

fixed onto the wall, and reinforced rendering, consisting in one or more layers and applied directly to the insulation. These systems should provide minimal thermal resistance in excess of $1 \mathrm{~m}^{2} \mathrm{~K} / \mathrm{W}$. Normally, in the Portuguese market, the insulation panels are expanded polystyrene (EPS), adhesively attached to the substrate and covered with a base coat reinforced with fibreglass mesh. The finish coat is a thin acrylic-based rendering (Figure 1).

The main advantages of ETICS, which have boosted its commercial growth, are $[1,2,4]$ as follows.

(i) Reduction of the thermal bridges and global heat losses due to the guaranteed continued thermal insulation of the building envelop (Figure 2). As a consequence, energy consumption decreases and health conditions inside the building improve because interior surface condensation on the wall singularities is reduced.

(ii) Increase of the effective interior area of the building's rooms. This may be due to thinner exterior walls when single-leaf walls are designed instead of cavity walls or because of the application of the thermal insulation on the wall's exterior side instead of the interior one, when the refurbishment of the façades implies higher thickness of insulation.

(iii) The insulation lies on the outside of the wall resulting in a higher thermal mass on the inside. This increases the thermal comfort during the cold season, as solar

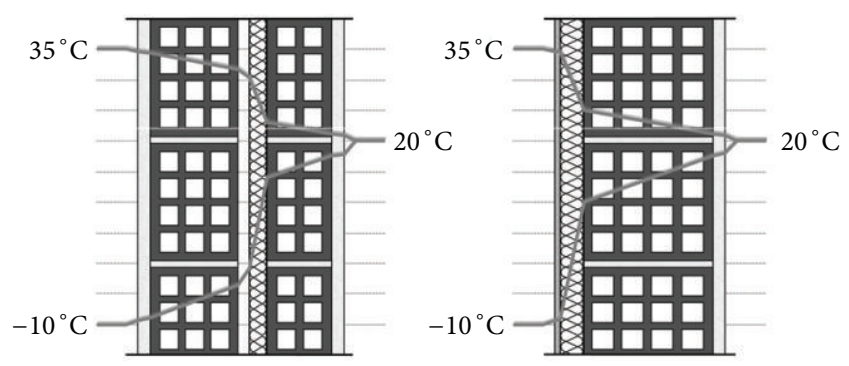

FIgURE 3: Temperature variation in exterior walls [4].

gains also increase, and during the warm season, delaying and moderating fluctuations of the heat flow that helps maintaining the building temperature.

(iv) Increase of the facades' durability as the masonry is better protected from the climate loads (thermal gradient-Figure 3, wind-driven rain, etc.).

(v) Ease of application and possibility to be installed without disturbing the building's dwellers, which are particularly important in refurbishment.

(vi) High variety of finishing solutions, providing a similar appearance to the traditional rendering.

Several defects have been stated during the last decades of ETICS application in building façades, namely, lack of flatness highlighted by an oblique angle of sunlight striking the surface, cracks in the rendering along the insulation board joints or starting at the windows corners, accumulated dirt due to rain water run-off, blistering or delamination of the finishing coating or of all rendering layers, lack of adhesiveness of the system causing its partial or total collapse, and so forth $[4,6,17]$. These defects are a result of design errors or bad workmanship. However, there are other two very relevant defects that are a characteristic of the system as it is manufactured nowadays.

(i) Low resistance to normal impact generated compressive stresses. This is a problem especially in accessible areas of the system and it not only has an aesthetic impact but also may compromise the system performance with respect to moisture protection from rain and exterior water vapour condensation (Figure 4).

(ii) Defacement of ETICS due to biological growth. Biological growth is due to high values of surface moisture content, which results from the combined effect of four parameters: wetting due to surface condensation, which occurs mainly during the nights with clear sky, wetting due to wind-driven rain, drying process, and properties of the exterior layer (Figure 5).

\section{Numerical Simulation of Hygrothermal Behaviour of ETICS}

Different models for the coupled heat, air, and moisture (HAM) transport have been developed and incorporated into 

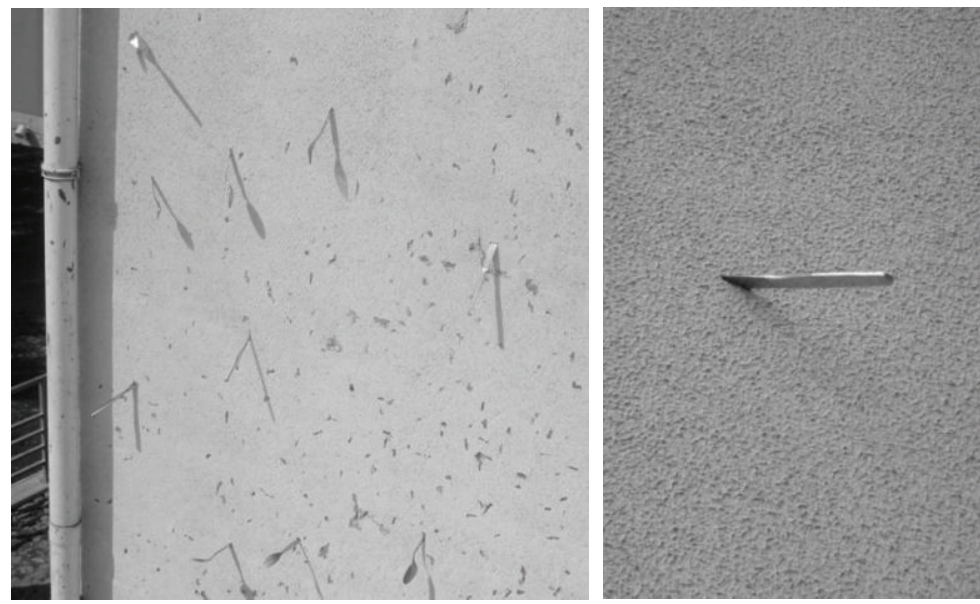

FIgUre 4: Damage of ETICS due to in-service impact (school building in Porto, Portugal).

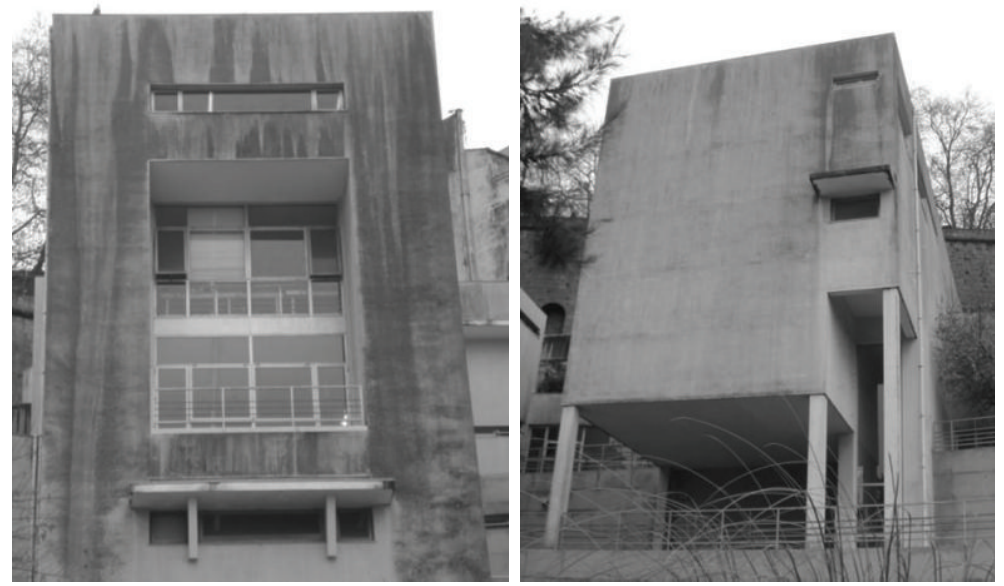

FIGURE 5: Defacement of ETICS due to biological growth (school building in Porto, Portugal).

various software programs used in the field of porous building materials. However, most of the hygrothermal models available to the public in general are not able to simulate properly the hygrothermal behaviour of ETICS, namely, the undercooling phenomenon, responsible for external surface condensation, and the effect of rain incident on the façade [18].

The software WUFI, developed by the Fraunhofer IBP in Germany, is a commercial tool with the ability to simulate the undercooling phenomenon as an explicit balance of the longwave radiation incident on the façade is used. The governing equations for moisture and energy transfer are, respectively [19],

$$
\begin{gathered}
\frac{\partial w}{\partial \phi} \frac{\partial \phi}{\partial t}=\nabla\left(D_{\phi} \nabla \phi+\delta_{p} \nabla\left(\phi p_{\text {sat }}\right)\right), \\
\frac{\partial H}{\partial T} \frac{\partial T}{\partial t}=\nabla(\lambda \nabla T)+h_{v} \nabla\left(\delta_{p} \nabla\left(\phi p_{\text {sat }}\right)\right),
\end{gathered}
$$

where $\partial w / \partial \phi$ is the moisture storage capacity $\left(\mathrm{kg} / \mathrm{m}^{3} \%\right)$, $\partial H / \partial T$ is the heat storage capacity of the moist building material $(\mathrm{J} / \mathrm{kg}), w$ is the moisture content $\left(\mathrm{kg} / \mathrm{m}^{3}\right), \lambda$ is the thermal conductivity $(\mathrm{W} / \mathrm{m} \cdot \mathrm{K}), D_{\phi}$ is the liquid conduction coefficient $(\mathrm{kg} / \mathrm{m} \cdot \mathrm{s}), \delta_{p}$ is the water vapour permeability $(\mathrm{kg} / \mathrm{m} \cdot \mathrm{s} \cdot \mathrm{Pa}), h_{v}$ is the evaporation enthalpy of the water $(\mathrm{J} / \mathrm{kg})$, $p_{\text {sat }}$ is the water vapour saturation pressure $(\mathrm{Pa}), T$ is the temperature $(\mathrm{K})$, and $\phi$ is the relative humidity (\%).

Regarding the treatment of the radiation effect on the exterior surface, WUFI uses an explicit balance of the longwave radiation, defining the surface emission, $I_{e}$, and the radiation reaching the façade, $I_{l}$. They are combined with the short-wave radiation components, $I_{s}$, into a collective heat source at the surface which may have positive or negative value, depending on the overall radiation balance: a positive value leads to heating up the component and a negative value leads to cooling it. With this methodology, the exterior heat transfer coefficient only contains the convective part [20, 21]:

$$
q=\alpha_{s} \times I_{s}+\varepsilon_{l, \text { surf }} \times I_{l}-I_{e} .
$$

In (2), the two first items give the total amount of radiation (short and long) reaching the surface, as, according to Kirchoff Law, the emissivity of a surface, $\varepsilon_{l, \text { surf }}$, is equal 


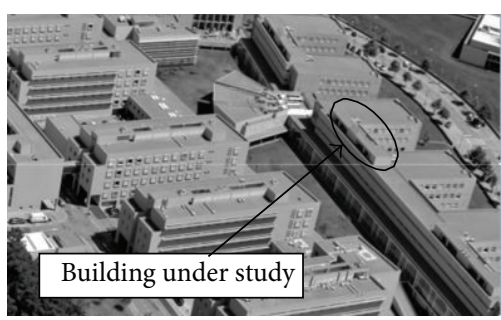

(a) Aerial view of the campaign site

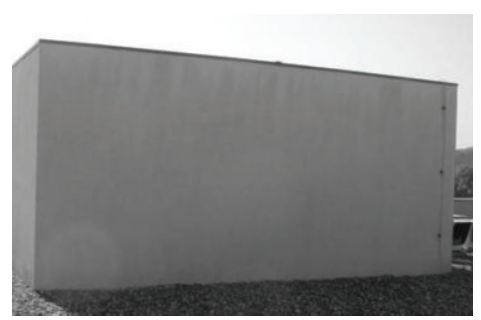

(b) West façade

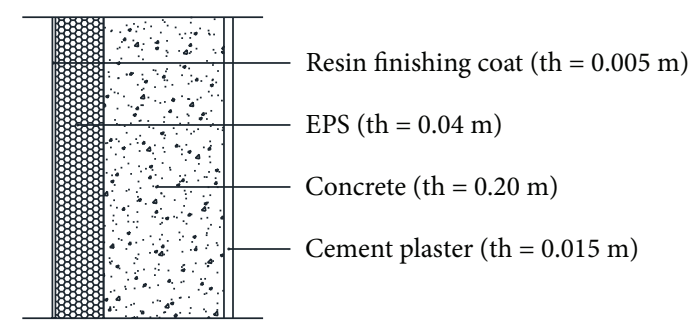

(c) Layers of the wall

FIgURE 6: Building under study, located in University of Porto campus, Portugal.

to its long-wave absorbance. The last item is the radiation emitted by the building surface. The total solar radiation, $I_{s}$, is described as a function of the direct solar radiation normal to component surface, $I_{s, \text { dir }}$, of the diffuse solar radiation, $I_{s \text {,dif }}$, affected by the atmospheric field of view, $g_{\text {atm }}$, and of the solar radiation reflected by the ground, $I_{s, \text { ref }}$, affected by the field of view of the ground, $g_{\text {ter }}$ :

$$
I_{s}=I_{s, \mathrm{dir}}+g_{\mathrm{atm}} \times I_{s, \mathrm{dif}}+g_{\mathrm{ter}} \times I_{s, \text { ref }} .
$$

The total long-wave radiation reaching the surface, $I_{l}$, depends on the downward atmospheric radiation, $I_{l, \text { atm }}$, affected by the atmospheric field of view, $g_{\mathrm{atm}}$. It also depends on the emission and reflection of long-wave radiation by the ground, both affected by the ground field of view, $g_{\text {ter }}$. Long-wave radiation emitted by the ground, $I_{l, \text { ter }}$, is calculated by the Stefan-Boltzmann Law, assuming that the ground has the same temperature as the air and inputting the ground long-wave emissivity. The atmospheric long-wave radiation reflected by the ground is calculated using the atmospheric long-wave radiation, $I_{l, \text { atm }}$, and the long-wave radiation reflectivity of the ground, $\rho_{\text {ter }}$ :

$$
I_{l}=g_{\mathrm{atm}} \times I_{l, \mathrm{~atm}}+g_{\mathrm{ter}} \times\left(I_{l, \mathrm{ter}}+\rho_{\mathrm{ter}} \times I_{l, \mathrm{~atm}}\right) .
$$

The sky radiation is ruled by the Plank Law, considering the concept of effective sky temperature, which can be defined as the temperature of a blackbody that emits the same amount of radiation as the sky [22]. The effective sky temperature depends on several atmospheric conditions, which are rarely available. For that reason, it is assumed that the sky behaves like a grey body, ruled by Stefan-Boltzmann Law, considering the sky emissivity and the air temperature near the ground [23].

The long-wave radiation emitted by the surface, $I_{e}$, depends on the surface emissivity, $\varepsilon_{l, \text { surf }}$, and temperature, $T_{\text {surf }}$, as it is ruled by the Stefan-Boltzmann Law:

$$
I_{e}=\varepsilon_{l, \text { surf }} \times \sigma \times T_{\text {surf }}^{4} .
$$

From the above equations, the direct solar radiation normal to component surface, $I_{s, \mathrm{dir}}$, is automatically calculated by the model from the direct solar radiation in horizontal surface, included in the climatic data, using information about the sun position. The diffuse solar radiation, $I_{s, \text { dif }}$, is obtained directly from the climatic data. The solar radiation reflected, $I_{s, \text { ref }}$, is calculated using solar radiation data (direct in horizontal surface and diffuse) and the short-wave radiation reflectivity of the ground. The atmospheric long-wave radiation, $I_{l \text {,atm}}$, necessary for the calculation is read directly from the climatic file, if it has this information available, or it may be calculated using the cloud index data [20,21].

To assess wind-driven rain (WDR), WUFI uses [20]

$$
\mathrm{WDR}=R_{h} \times\left(R_{1}+R_{2} \times v_{10} \times \cos \theta\right),
$$

where WDR is the wind-driven rain intensity $(\mathrm{mm} / \mathrm{h}), R_{h}$ is the horizontal rainfall amount $(\mathrm{mm} / \mathrm{h}), R_{1}$ is a driving rain coefficient that depends on the construction element (is equal to 0 for façades), $R_{2}$ is a driving rain coefficient that depends on the position on the façade, $v_{10}$ is reference wind speed at $10 \mathrm{~m}$ above ground $(\mathrm{m} / \mathrm{s})$, and $\theta$ is the angle between the wind direction and the normal to the façade $\left({ }^{\circ}\right)$.

\section{Validation of the Numerical Model}

4.1. Experimental Set-Up. An "in situ" test campaign was carried out during one year, from March 2009 to February 2010. Instruments were set up on the west façade covered with ETICS of a building located in the University of Porto campus (Figure 6). T-type thermocouples set up on the façade under study provided information about the surface temperature and WDR gauges measured the amount of rain incident on the façade (black dot in Figure 7). At the same time, climate parameters were also collected by the Building Physics Laboratory Weather Station, located near the building under study (Figure 7). Air temperature and relative humidity were also collected inside the building. The annual averages of the outdoor and indoor climate are presented in Table 1. Information regarding the accuracy and calibration of the surface devices and about the weather station is given by Barreira [25].

4.2. Parameters for the Numerical Simulation. The hygrothermal software tool that was used to perform the simulations was WUFI 1D (Section 3). Its inputs are the material properties of each layer of the building component under study, orientation, inclination and height of the building component, the surface transfer coefficients of the interior and exterior layer, the radiant characteristics of the ground, and the initial moisture and temperature in the component. The hourly parameters of indoor and outdoor climate are also required. The outputs of the simulations are hourly values of 


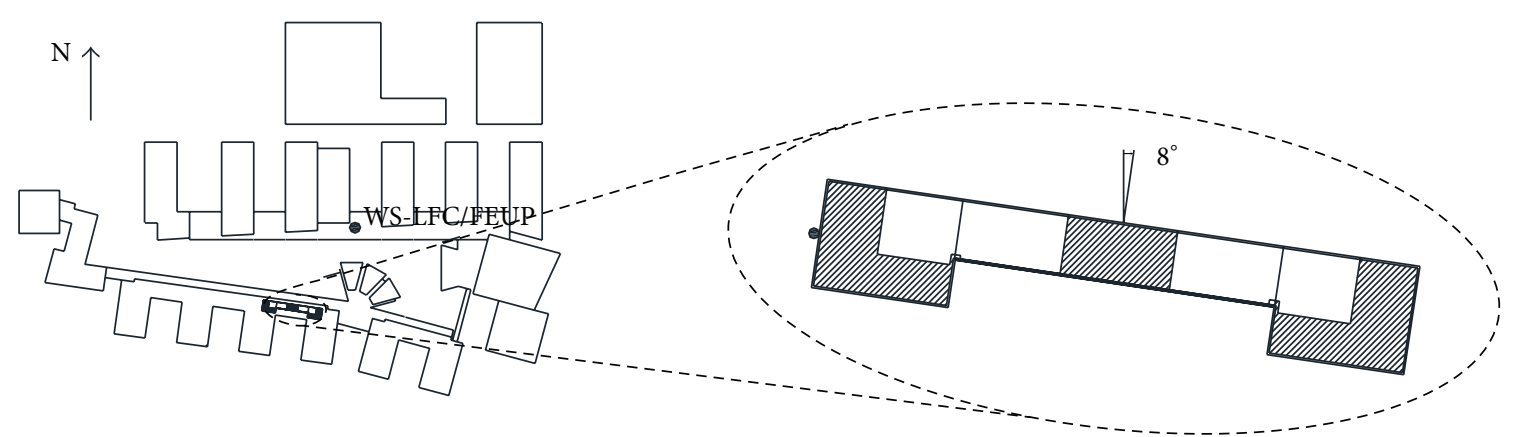

FIGURE 7: Layout with the surface devices and weather station locations.

TABLE 1: Outdoor and indoor climate during the test campaign (annual average).

\begin{tabular}{lcc}
\hline \multirow{2}{*}{ Climatic parameter } & \multicolumn{2}{c}{ Annual average } \\
& Outdoor & Indoor \\
\hline $\begin{array}{l}\text { Temperature } \\
\text { Relative humidity }\end{array}$ & $15.4^{\circ} \mathrm{C}$ & $20.3^{\circ} \mathrm{C}$ \\
$\begin{array}{l}\text { Global radiation emitted by } \\
\text { the sun }\end{array}$ & $72 \%$ & $69 \%$ \\
$\quad \begin{array}{l}\text { Annual ave. of the positive } \\
\text { values only* }\end{array}$ & $254 \mathrm{~W} / \mathrm{m}^{2}$ & - \\
$\quad \begin{array}{l}\text { Annual max. value } \\
\text { Radiation emitted by the sky }\end{array}$ & $1122 \mathrm{~W} / \mathrm{m}^{2}$ & - \\
Wind velocity/direction & $335 \mathrm{~W} / \mathrm{m}^{2}$ & - \\
\hline Climatic parameter & $1.4 \mathrm{~m} / \mathrm{s} / 170^{\circ}$ & - \\
\hline Rain & Annual accumulated value \\
\hline${ }^{*}$ The null values, corresponding to night-time, were not considered in the \\
average calculation.
\end{tabular}

surface temperature of the exterior layer and amount of rain that reaches the façade.

The simulations were run using the wall from Figure 6(c). The materials used in each layer were selected from software database, which also gives the material thermal and hygric properties necessary for simulations. No changes were made to them, except for the exterior rendering, whose adopted properties are shown in Table 2, considering a single layer as the base coat has similar properties to the finishing coat. These properties were collected from the technical sheets of the products used in the wall.

The surface transfer coefficients used in the simulations are shown in Table 3. The wall was simulated facing west and belonging to the upper part of a tall building (WDR coefficient or $R_{2}=0.2 \mathrm{~s} / \mathrm{m}$ ). The hourly climatic data used for the simulations were measured in the real conditions of use and the annual averages are presented in Table 1.

\subsection{Comparison between Simulated and Measured Values}

4.3.1. Surface Temperature. Figure 8 shows surface temperature variation, measured and calculated, on the west façade, during one day of November 2009 and the cumulative
TABLE 2: Properties of the exterior rendering (resin finishing coat).

\begin{tabular}{lc}
\hline Property & $\begin{array}{c}\text { Adopted } \\
\text { value }\end{array}$ \\
\hline Basic properties & 1600 \\
Bulk density $\left(\mathrm{kg} / \mathrm{m}^{3}\right)$ & 0.2 \\
Porosity $\left(\mathrm{m}^{3} / \mathrm{m}^{3}\right)$ & 850 \\
Heat capacity $(\mathrm{J} / \mathrm{kg} \cdot \mathrm{K})$ & 1 \\
Heat conductivity dry $(\mathrm{W} / \mathrm{m} \cdot \mathrm{K})$ & 25 \\
$\begin{array}{l}\text { Diffusion resistance factor dry }(-) \\
\text { Additional hygrothermal functions }\end{array}$ & \\
Moisture storage function & No* \\
Liquid transport coefficients for suction & 0 \\
and redistribution $\left(\mathrm{m}^{2} / \mathrm{s}\right)$ & $\begin{array}{c}\text { Not } \\
\text { Water vapour diffusion resistance factor, } \\
\text { moisture-dependent }\end{array}$ \\
$\begin{array}{l}\text { Thermal conductivity, } \\
\text { moisture-dependent }\end{array}$ & $\begin{array}{c}\text { Not } \\
\text { dependent }\end{array}$ \\
\hline
\end{tabular}

${ }^{*}$ It was assumed that the exterior rendering has no hygroscopic behaviour.

TABLE 3: Surface transfer coefficients in numerical simulations.

Surface transfer coefficients

Exterior convective heat transfer coefficient $\left(\mathrm{W} / \mathrm{m}^{2} \cdot \mathrm{K}\right)$

Leeward:

$\alpha_{c}=0.33 \times v_{\text {wind }}+4.5$

Windward:

$\alpha_{c}=0.16 \times v_{\text {wind }}+4.5$

Short-wave radiation absorbance

(exterior rendering)

0.35

Long-wave radiation emissivity (exterior rendering)

Long-wave radiation emissivity (ground) $\quad 0.90$ (measured value)

Short-wave radiation reflectance

(ground)

0.20

Long-wave radiation reflectance (ground) 0.10

Interior heat resistance $\left(\mathrm{m}^{2} \cdot \mathrm{K} / \mathrm{W}\right) \quad 0.125$

Rain absorption factor $\quad 0.70$

distribution function considering the whole month. The results show that there is a good agreement between the 

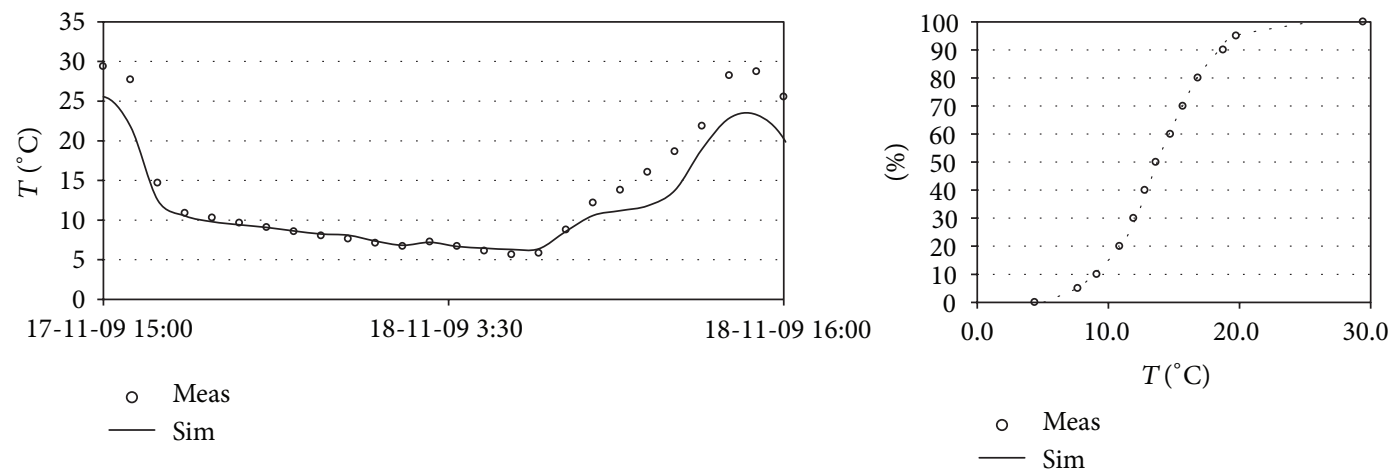

FIGURE 8: Variation in time and the cumulative distribution function of surface temperature on west façade in November 2009, with clear sky (measurements versus numerical simulation).

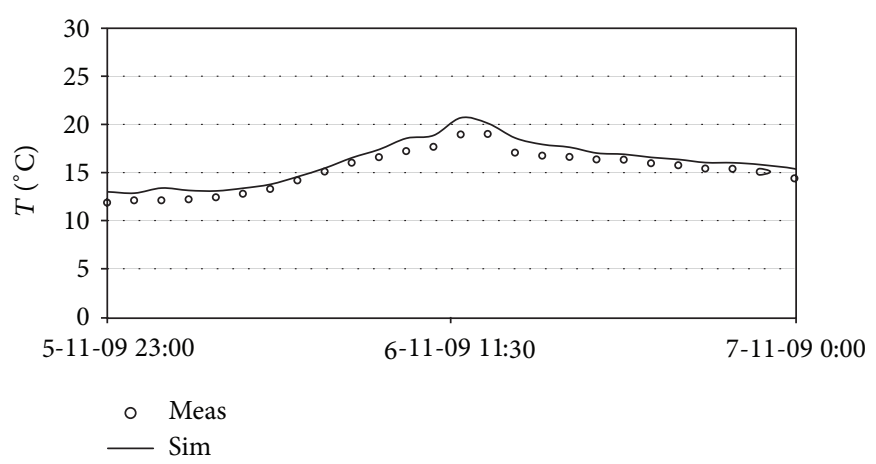

Figure 9: Variation in time of surface temperature on west façade in November 2009, with cloudy sky (measurements versus numerical simulation).

simulated and measured values, especially during the night when temperatures were lower. During daylight, with clear sky, the measured values are higher than the simulated values, which may be related to inaccuracies in the calculation of the sun position in the horizon, which influences the amount of direct solar radiation incident on the façade. The differences obtained between simulated and measured values when the sky is clear are less relevant when the sky is cloudy, as shown in Figure 9. Similar results were obtained when comparing measured and calculated values of surface temperature for the whole year under study.

4.3.2. Wind-Driven Rain. Figure 10 shows that the measured and calculated values are quite similar, although the simulated values are always higher than the measured values. That may be related, as stated by Nore et al. [26], to evaporation of adhesion water from the gauge collection area or from the reservoir, slashing of drops from the collection area at impact, and so forth. Similar results were obtained for the whole year under study.

\section{Critical Parameters Involved in Hygrothermal Behaviour of ETICS}

5.1. Introductory Notes. In this paragraph, the results of a sensitivity analysis, performed based on numerical simulations, are presented. Those results support a discussion on the relevance of each parameter for the surface condensation, wind-driven rain, and drying process. The parameters under discussion were divided into four categories:

(a) properties of the exterior layer: moisture diffusivity, water vapour resistance, emissivity, absorbance to solar radiation, and thickness;

(b) characteristics of the façade: orientation, height of the building, and total thermal resistance;

(c) exterior climate: temperature, relative humidity, solar radiation, atmospheric radiation, wind velocity, wind direction, and rain;

(d) interior hygrothermal conditions: temperature and relative humidity.

To assess the influence of each parameter, WUFI was used to perform the numerical simulations. The simulations were run considering the conditions described in Section 4, except for outdoor and indoor climate. The hourly outdoor climatic data of Porto, Portugal, was numerically generated by the commercial software Meteonorm 6 [24]. Table 4 shows the average of the climatic parameters. Indoor temperature and relative humidity were set to be constant: indoor temperature was set to be $20^{\circ} \mathrm{C}$ and indoor relative humidity was set to be $60 \%$. Although this is not a realistic situation, these values 

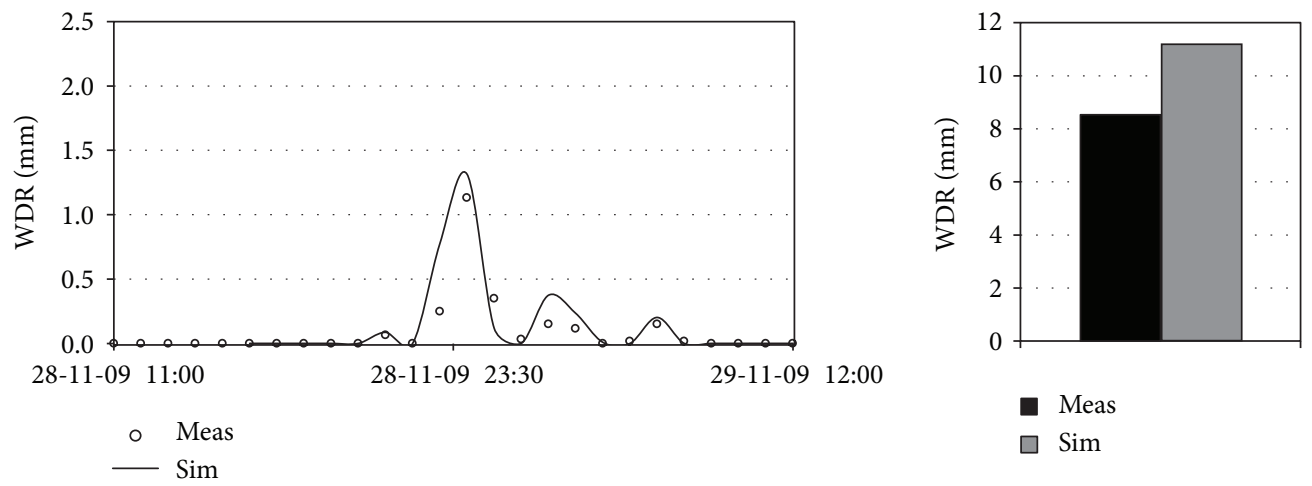

FIGURE 10: Variation in time and accumulated values of WDR on west façade in November 2009 (measurements versus numerical simulation).

TABLE 4: Porto climate generated by the commercial software Meteonorm 6 [24].

\begin{tabular}{lc}
\hline Climatic parameter & Annual average \\
\hline Temperature & $14.8^{\circ} \mathrm{C}$ \\
Relative humidity & $78 \%$ \\
$\begin{array}{l}\text { Global radiation emitted by the sun } \\
\quad \begin{array}{l}\text { Annual ave. of the positive values } \\
\text { only }\end{array}\end{array}$ \\
$\begin{array}{l}\text { Radiation emitted by the sky } \\
\text { Wind velocity/direction }\end{array}$ & $343 \mathrm{~W} / \mathrm{m}^{2}$ \\
\hline
\end{tabular}

Climatic parameter Annual accumulated value

Rain $779 \mathrm{~mm}$

${ }^{*}$ The null values, corresponding to night-time, were not considered in the average calculation.

were adopted for the sake of simplicity and considering that the phenomenon under study occurs outdoors.

For the sensitivity analyses, each parameter was changed individually, in a range selected based on the likelihood of the variation. It must be clarified that the new exterior climate created for each simulation is not real and the existing correlation between climatic parameters was not considered in this analysis.

5.2. Exterior Surface Condensation. Exterior surface condensation occurs mostly during the night, when the exterior surface temperature is lower than the dew point temperature, as a result of long-wave radiation exchange between the surface and the atmosphere. During clear nights, the atmosphere's emitted radiation decreases considerably and the radiation emitted by the surface is greater than the one that reaches the surface, causing a loss of radiation towards the sky. This negative balance on the surface is maintained until heat transport by convection and by conduction compensates for the loss by radiation [27].

Exterior surface condensation can be analyzed using psychrometry principles. When water vapour partial pressure of the air is greater than the water vapour saturation pressure at the surface, condensation will occur [28]. According to Zheng et al. [29], the difference between the water vapour partial pressure in the air $\left(P_{v}\right.$ (air) in $\left.\mathrm{Pa}\right)$ and the water vapour saturation pressure on the surface $\left(P_{\text {sat }}\right.$ (surface) in $\mathrm{Pa}$ ) may be called Condensation Potential (CP in $\mathrm{Pa}$ ), which implies condensation for positive values. CP can be understood as the amount of water vapour that is available to condensate:

$$
\mathrm{CP}=P_{v}(\text { air })-P_{\text {sat }}(\text { surface }) .
$$

The same author states that both positive $\mathrm{CP}$ and its lasted time should be considered to evaluate the amount of condensation. The product of positive $\mathrm{CP}\left(\mathrm{CP}_{(>0)}\right.$ in $\left.\mathrm{Pa}\right)$ by its lasted time $\left(\Delta t_{\mathrm{CP}_{(>0)}}\right.$ in $\left.\mathrm{h}\right)$ may be called Condensation Potential Equivalent (CPE in $\mathrm{Pa} \cdot \mathrm{h}$ ) and allows estimating the amount of condensated water. To estimate the risk of condensation for a certain period of time, $\mathrm{CPE}$ must be accumulated in time $\left(\mathrm{CPE}_{a}\right)$ :

$$
\mathrm{CPE}=\mathrm{CP}_{(>0)} \cdot \Delta t_{\mathrm{CP}_{(>0)}} .
$$

5.3. Drying Process. The drying process allows the evaporation of the liquid water accumulated on the surface due to the surface condensation and WDR. Evaporation from the wet surface occurs whenever the saturation pressure at the surface is greater than the vapour pressure of the ambient air [28]. If the drying process is not sufficiently fast, the surface moisture content remains high for long periods and increases the risk of microbiological growth [10].

As condensation, also the drying capacity of a wet surface can be analyzed using psychrometry principles [28]. By analogy, it is possible to establish the concept of Drying Potential ( $\mathrm{DP}$ in $\mathrm{Pa}$ ) being the difference between the water vapour saturation pressure on the surface $\left(P_{\text {sat }}\right.$ (surface) in $\mathrm{Pa})$ and the water vapour partial pressure in the air $\left(P_{v}\right.$ (air) in $\mathrm{Pa}$ ), which implies evaporation for positive values. DP can be understood as the amount of water vapour transferred to the air, considering that the surface remains permanently wet:

$$
\mathrm{DP}=P_{\text {sat }}(\text { surface })-P_{v}(\text { air }) .
$$

To evaluate the maximum ability to dry out, the product of positive $\mathrm{DP}\left(\mathrm{DP}_{(>0)}\right.$, in $\left.\mathrm{Pa}\right)$ by its lasted time. $\left(\Delta t_{\mathrm{DP}_{(>0)}}\right.$, in h) shall be considered and may be called Drying Potential 
TABLE 5: Relevance of the parameter values and expected variations in terms of surface condensation $(C)$, WDR, and drying process $(D)$.

\begin{tabular}{|c|c|c|c|c|c|}
\hline \multirow{2}{*}{ Parameter } & \multirow{2}{*}{ Initial situation } & \multirow{2}{*}{ Variation } & \multicolumn{3}{|c|}{ Relevance } \\
\hline & & & $C$ & WDR & $D$ \\
\hline \multicolumn{6}{|l|}{ Properties of the exterior layer } \\
\hline Moisture diffusivity, in $\left(\mathrm{m}^{2} / \mathrm{s}\right)$ & 0 & $0.0013^{*}$ & $\#$ & \# & \# \\
\hline Water vapour diffusion resistance factor & 25 & 1000 & \# & \# & $\#$ \\
\hline Emissivity (Figure 11) & 0.85 & 0.60 & \#\#\# & $\#$ & $\#$ \\
\hline Absorbance to solar radiation (Figure 12) & 0.35 & 0.50 & $\#$ & $\#$ & \#\# \\
\hline Thickness, in (m) & 0.005 & 0.02 & $\#$ & $\#$ & $\#$ \\
\hline \multicolumn{6}{|l|}{ Characteristics of the façade } \\
\hline Orientation (Figure 13) & $\mathrm{W}$ & $\mathrm{N} ; \mathrm{E} ; \mathrm{S}$ & $\#$ & $\# \#$ & \#\# \\
\hline Height of the building (Figure 14) & Tall & Small & \# & \#\#\# & \# \\
\hline Total thermal resistance (Figure 15) & $e_{\mathrm{EPS}}=0.04 \mathrm{~m}$ & $e_{\mathrm{EPS}}=0.06 \mathrm{~m}$ & $\# \#$ & $\#$ & \# \\
\hline \multicolumn{6}{|l|}{ Exterior climate } \\
\hline Temperature, in $\left({ }^{\circ} \mathrm{C}\right)$ (Figure 16$)$ & $T_{\text {Porto }}$ & $T_{\text {Porto }}-2$ & \#\#\# & \# & \# \\
\hline Relative humidity, in (\%) (Figure 17) & $\mathrm{HR}_{\text {Porto }}$ & $\mathrm{HR}_{\text {Porto }}-5$ & $\# \#$ & \# & $\#$ \\
\hline Solar radiation, in $\left(\mathrm{W} / \mathrm{m}^{2}\right)$ (Figure 18$)$ & $I_{s \text {-Porto }}$ & $0.70 \times I_{s \text {-Porto }}$ & $\#$ & $\#$ & \#\# \\
\hline Atmospheric radiation, in $\left(\mathrm{W} / \mathrm{m}^{2}\right)$ (Figure 19) & $I_{\text {atm-Porto }}$ & $1.05 \times I_{\text {atm-Porto }}$ & \#\#\# & \# & $\#$ \\
\hline Wind velocity, in (m/s) (Figure 20) & $W_{v \text {-Porto }}$ & $0.90 \times W_{v \text {-Porto }}$ & $\#$ & \#\# & \# \\
\hline Wind direction, in $\left(^{\circ}\right)$ & $\operatorname{Dir}_{v \text {-Porto }}$ & $\operatorname{Dir}_{v \text {-Porto }}+180$ & $\#$ & \#\# & $\#$ \\
\hline Rain, in (mm) (Figure 21) & Rain $_{\text {Porto }}$ & $0.20 \times$ Rain $_{\text {Porto }}$ & $\#$ & \#\#\# & $\#$ \\
\hline \multicolumn{6}{|l|}{ Interior climate } \\
\hline Temperature, in $\left({ }^{\circ} \mathrm{C}\right)$ (Figure 22$)$ & 20 & 22 & \#\# & $\#$ & $\#$ \\
\hline Relative humidity, in (\%) & 60 & 65 & $\#$ & $\#$ & $\#$ \\
\hline
\end{tabular}

${ }^{*}$ For moisture content at $80 \%$ of RH (WUFI database).

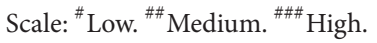

Equivalent (DPE in Pa.h). To estimate this ability for a certain period of time, DPE must be accumulated in time $\left(\mathrm{DPE}_{a}\right)$ :

$$
\mathrm{DPE}=\mathrm{DP}_{(>0)} \cdot \Delta t_{\mathrm{DP}_{(>0)}} .
$$

It must be stated that $\mathrm{DPE}_{a}$ is not useful as a parameter for modelling the real drying capacity of a wet surface, as it is not permanently saturated. After some time, the liquid water evaporates and the vapour pressure at the surface depends not only on the surface temperature, but also on its relative humidity. However, to simplify the parameters used to evaluate the drying process, $\mathrm{DPE}_{a}$ can be employed as an overvalued drying capacity.

5.4. Discussion of the Results. Table 5 shows a qualitative analysis of the results obtained in the simulations and points the relevance of each parameter in surface condensation, WDR, and drying process, by comparing, respectively, the annual accumulated values of CPE, WDR, and DPE calculated for the initial situation with the ones obtained after changing the parameter under study.

The results show that the parameters that most influence surface condensation are exterior relative humidity, atmospheric radiation, exterior temperature, and emissivity, followed by the total thermal resistance of the wall and the interior temperature. The most relevant parameters in the drying process are absorbance to short-wave radiation, solar radiation, and orientation. Wind-driven rain is most influenced by rain, height of the building, wind velocity, wind direction, and orientation. Figures 11 to 22 show the results obtained for the parameters that most influence surface condensation, WDR, and drying process.

Different values adopted for the exterior layer emissivity and absorbance to short-wave radiation may change the surface temperature. The emissivity rules the amount of longwave radiation emitted by the surface and, consequently, the loss of heat by radiation. The greater the emissivity is, the higher the radiation emitted by the surface is and the greater the drop of the surface temperature is. This phenomenon occurs both during the day and during the night but has more impact for the night period as during the day, the sun effect is preponderant (Figure 11). The absorbance coefficient to shortwave radiation influences the solar radiation absorbed by the wall during the day and changes the surface temperature. Its effect on surface temperature is quite relevant during the day, but, during the night, due to the small thermal capacity of the rendering layer, the heat stored is rapidly lost and temperatures only increase slightly (Figure 12). Similar studies carried out by the Fraunhofer IBP point these same conclusions, both for emissivity and for absorbance to shortwave radiation, considering the Holzkirchen climate [10, 27, 30,31 . WDR does not depend on exterior layer emissivity and absorbance to short-wave radiation.

The wall orientation has some influence on the surface temperature and on the amount of rain that reaches the façade (Figure 13). During the day, the surface temperature variation 

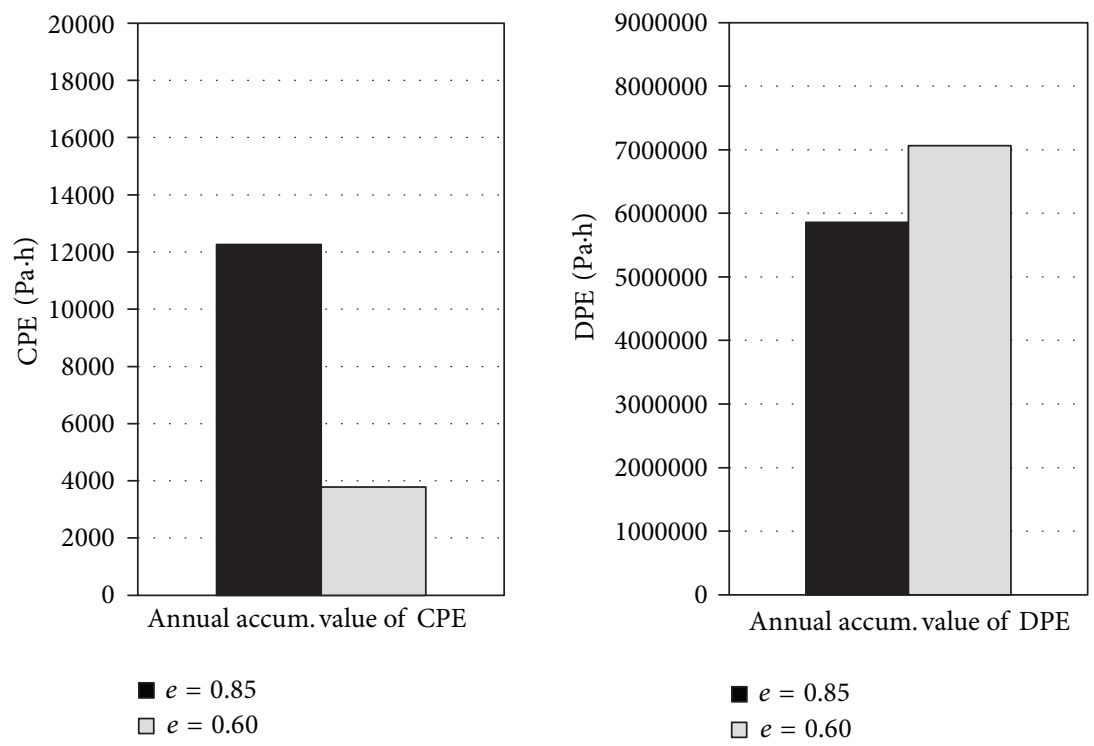

FIGURE 11: Properties of the exterior layer: emissivity.
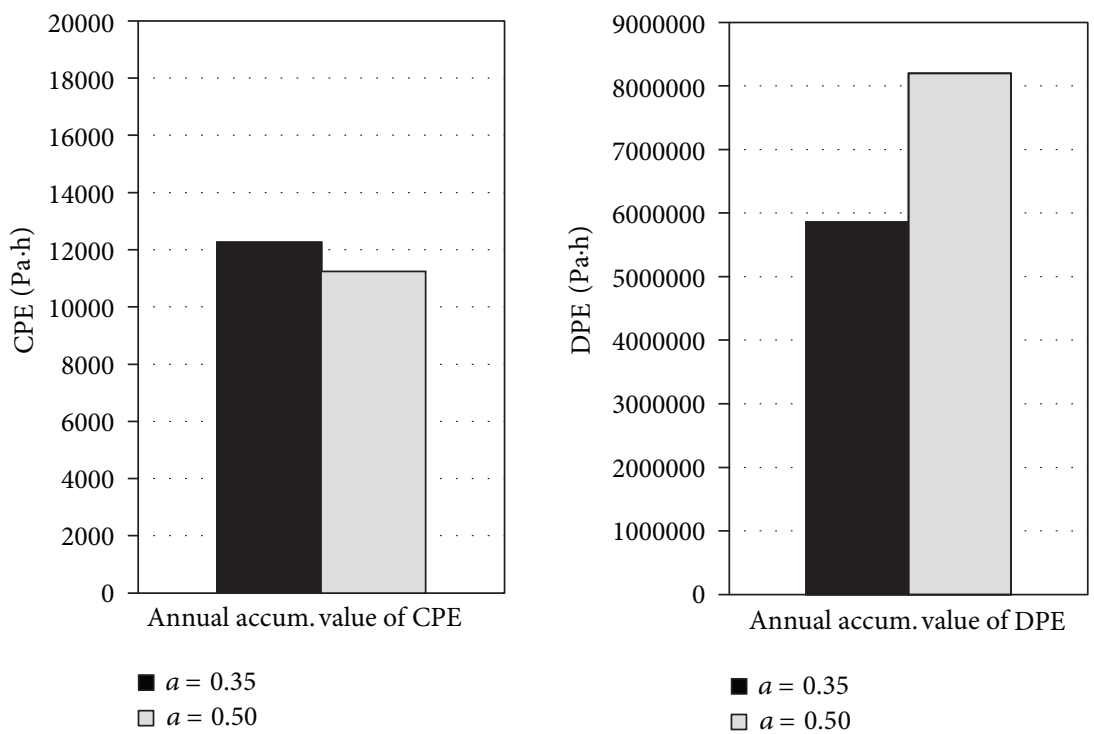

FIgURE 12: Properties of the exterior layer: absorbance to solar radiation.

is related to the amount of direct solar radiation incident on the façade. During the night, the loss of heat by radiation does not depend on orientation. Consequently, the drying capacity is higher in the south façade and lower in the north façade and the condensation is almost similar for all orientations. The studies carried out by Zillig et al. [30] and Holm et al. [27] also point small differences on the amounts of condensation with orientation. However, the variation of condensation with orientation is not similar, as Fraunhofer IBP pointed that the west façade had higher condensation followed by north, south, and east, which is not in accordance with Figure 13. This difference in the results may be due to different climatic conditions and parameters assumed for the simulations.
WDR also depends on the façade orientation as the combined effect of rain and wind is only taken into account if the wind is facing the façade. The annual accumulated WDR value is lower than the expected value. That may be justified by the fact that calculated values of WDR depend considerably on the model used in the simulation. As stated by Freitas et al. [32], there are significant differences between the values obtained using different WDR models. Also, the amount of rain in a horizontal plane given by Meteonorm is lower than the expected value (Tables 1 and 4).

The height of the building has no impact on the surface temperature of the façade (Figure 14). Although the wind velocity increases with the distance from the ground and, 

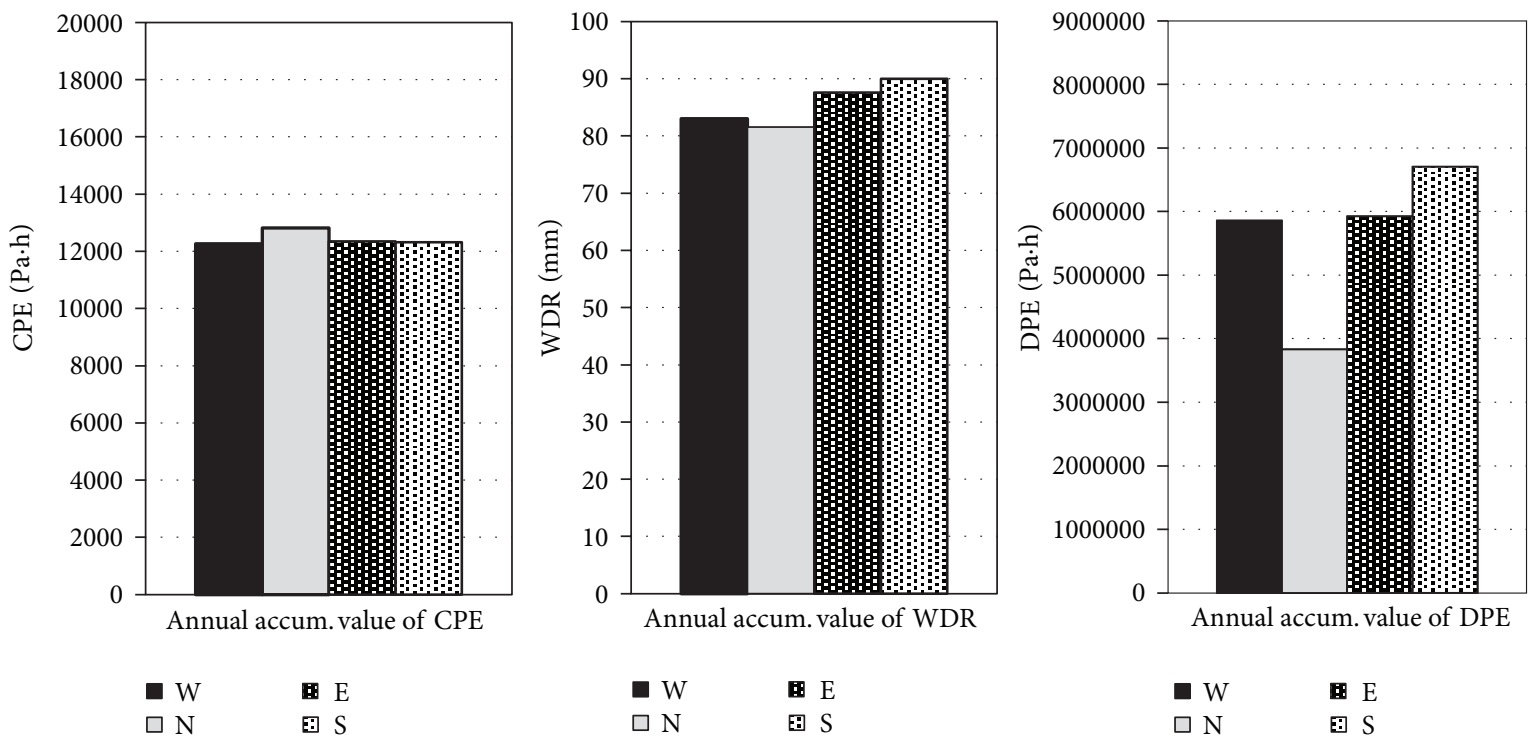

FIGURE 13: Characteristics of the façade: orientation.
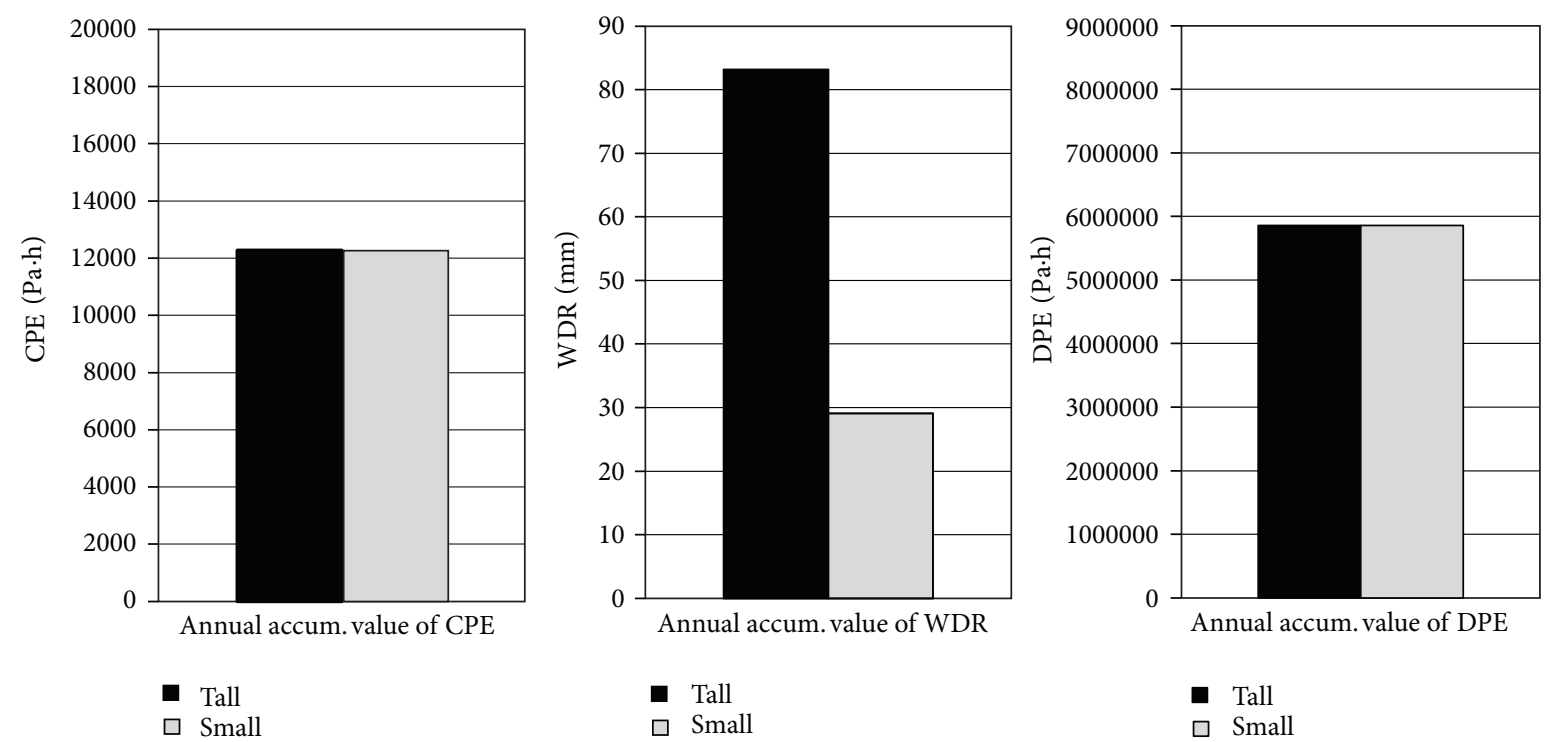

FIGURE 14: Characteristics of the façade: height of the building.

consequently, the heat exchanges by convection between the surface and the air, hygrothermal models do not take this variation of convective heat transfer coefficient with height into account [33]. Therefore, neither condensation nor the drying capacity is influenced by the height of the building. In WDR, the building height has great impact, as WDR coefficients are a function of the distance between the surface and the ground and its exposure to the wind [20].

The total thermal resistance of the wall induces changes in heat transfer from the indoor environment, especially during the night when there is no effect of the sun. Increasing the total thermal resistance of the wall (by increasing, e.g., the thickness of the thermal insulation), the heat flow that reaches the exterior surface of the wall during the night decreases and surface temperature drops. Lower surface temperature worsens surface condensation [27, 30]. During the day, due to solar gains, the heat transfer by conduction is not relevant on the exterior surface temperature and, consequently, the drying capacity does not depend on the total thermal resistance of the wall. Also the WDR is not affected by the total thermal resistance of the wall (Figure 15).

Exterior temperature and relative humidity are two of the most relevant climatic parameters regarding surface condensation, not only because they control water vapour partial pressure of the air, but also because they influence the surface temperature and, consequently, the water vapour saturation pressure on the surface. A decrease in the air temperature causes a decrease of the surface temperature and of the dew 

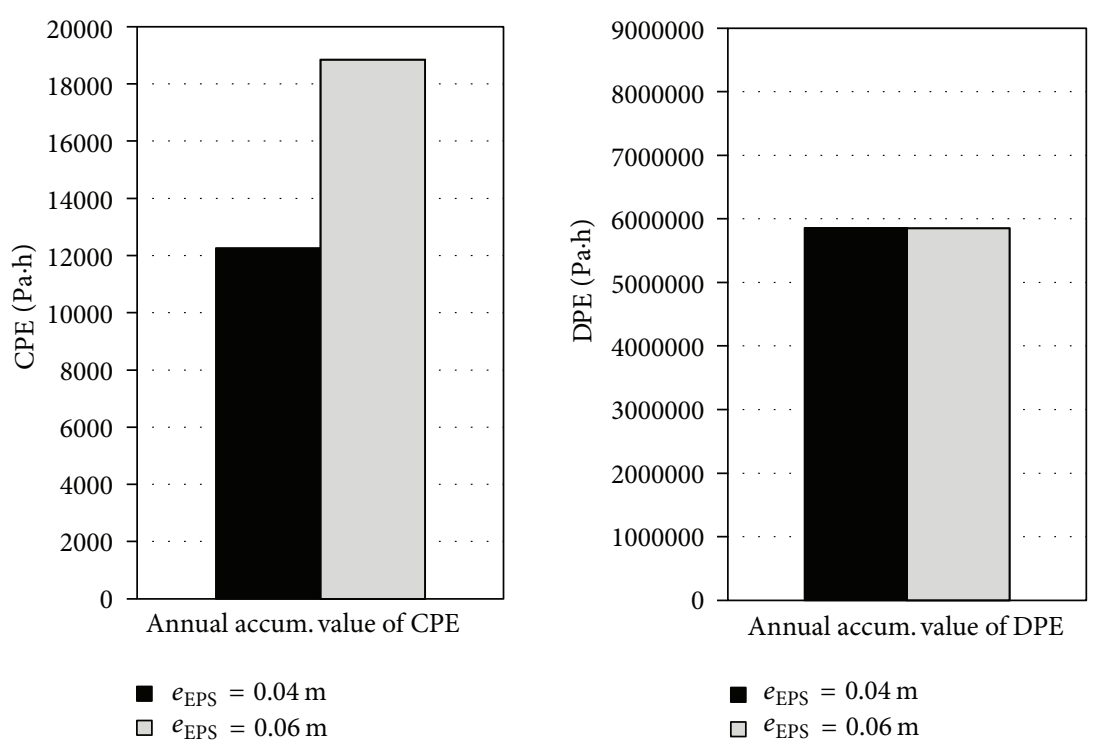

FIGURE 15: Characteristics of the façade: total thermal resistance.
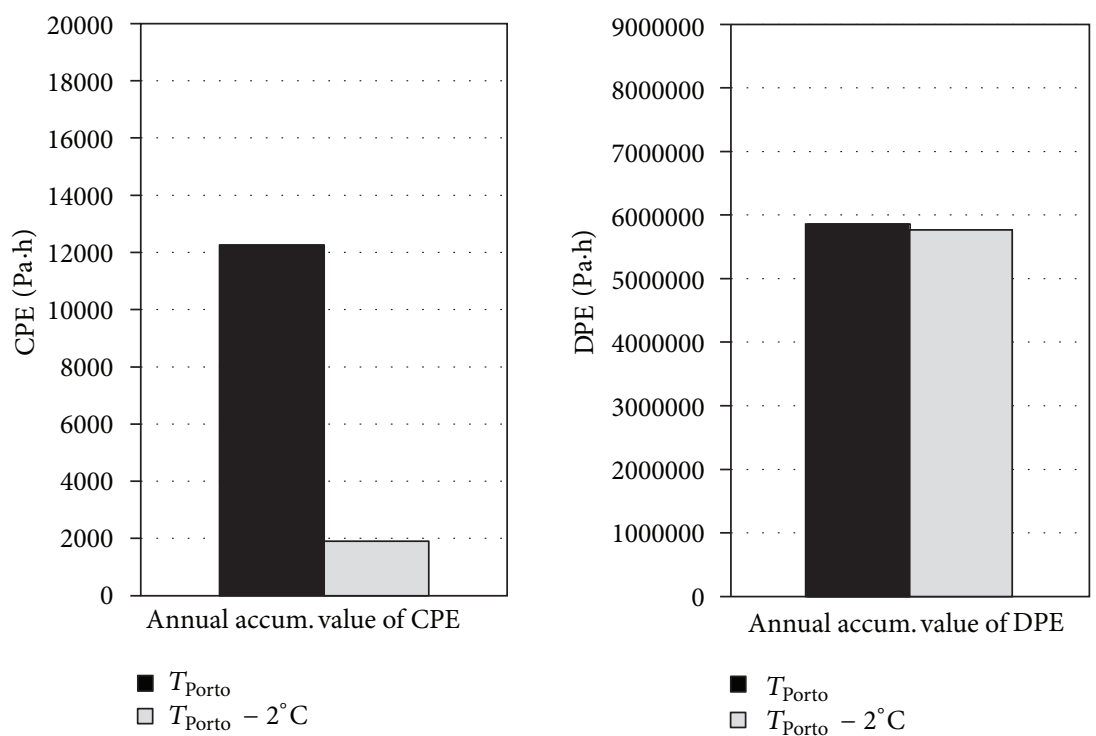

FIgURE 16: Exterior climate: temperature.

point temperature. However, as the drop is higher for the dew point temperature, condensation reduces. A decrease in the air relative humidity causes a very small decrease in surface temperature and a more marked decreases in dew point temperature, reducing condensation. The influence of temperature and relative humidity in the drying process is not very relevant, although a decrease in the relative humidity increases the drying capacity. WDR does not depend on exterior temperature and relative humidity (Figures 16 and 17).

The influence of global solar radiation (direct plus diffuse) is not very relevant in surface condensation. As it was stated for the absorbance to short-wave radiation, the solar radiation affects mainly the surface temperature during the day and, consequently, the drying capacity, as the lower heat load applied results on a cooler surface. WDR is not influenced by solar radiation (Figure 18).

The atmospheric radiation has a significant impact on surface condensation. The higher the atmospheric radiation emitted by the sky is, the higher the radiation adsorbed by the surface is. During the night, this increase of absorbed radiation reduces the negative radiant balance on the façade surface, which leads to a smaller drop in the surface temperature and consequently decreases condensation. The increase of long-wave radiation adsorbed by the surface also increases surface temperature during the day, but its effect on the drying process is not very relevant. WDR is not influenced by solar radiation (Figure 19). 

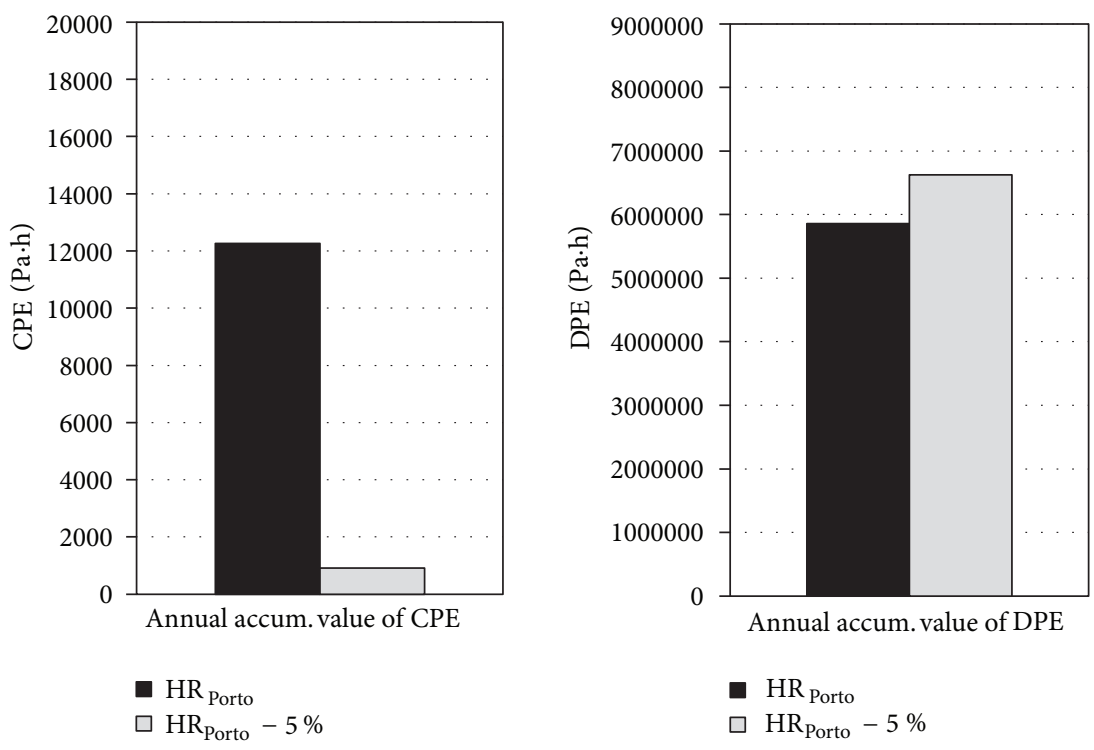

FIGURE 17: Exterior climate: relative humidity.
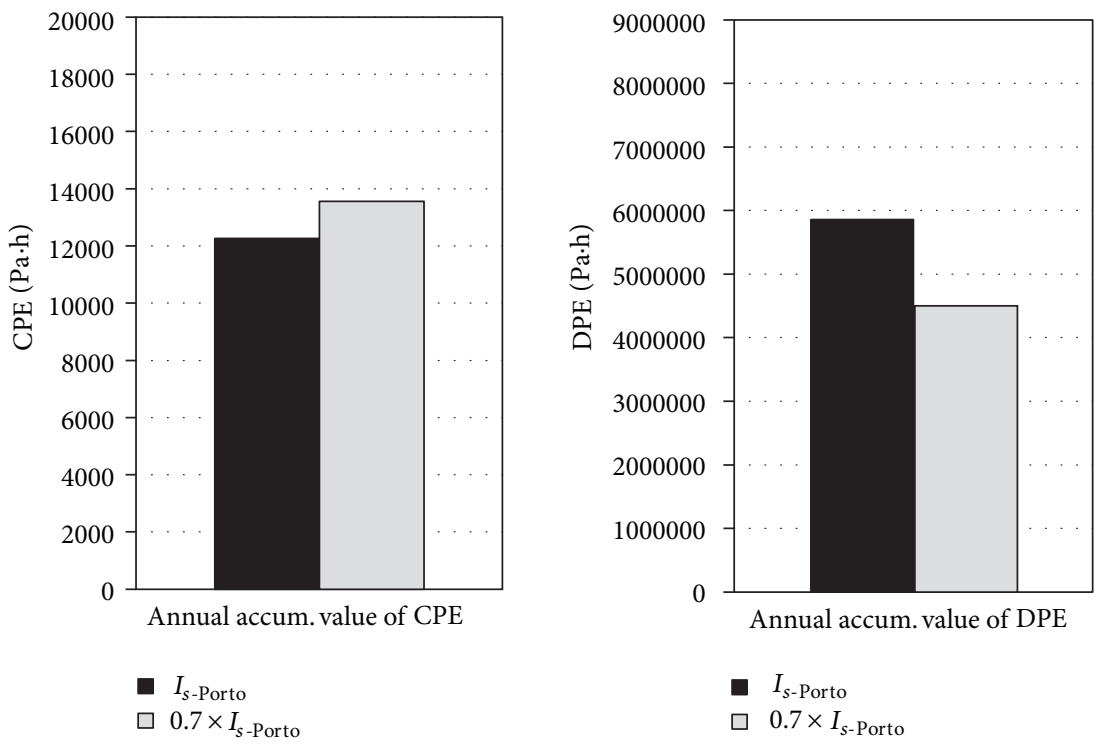

FIGURE 18: Exterior climate: solar radiation.

Rain, wind velocity and wind direction influence mostly the amount of rain that reaches the façade because they are key parameters to calculate WDR. Although the wind induces changes in heat transfer by convection near the surface and, consequently, influences the surface temperature of the wall, it has no real impact on condensation and on the drying process (Figures 20 and 21).

Interior temperature induces changes in heat transfer by conduction from the indoor environment, especially during the night when there is no effect of the sun. Higher interior temperature increases the heat flow that reaches the exterior surface of the wall and also increases the exterior surface temperature. Condensation reduces due to an increase of the interior temperature and the drying capacity is slightly higher. WDR does not depend on interior temperature (Figure 22).

\section{Conclusions}

The results of the sensitivity analysis, performed for Porto Portugal, show that the parameters that most influence surface condensation are exterior relative humidity, atmospheric radiation, exterior temperature, and emissivity, followed by the total thermal resistance of the wall and the interior air temperature. The most relevant parameters in the drying process are the ones related to the effect of the sun in the wall: absorbance to short-wave radiation, solar radiation, and orientation. Wind-driven rain is most influenced by rain, 

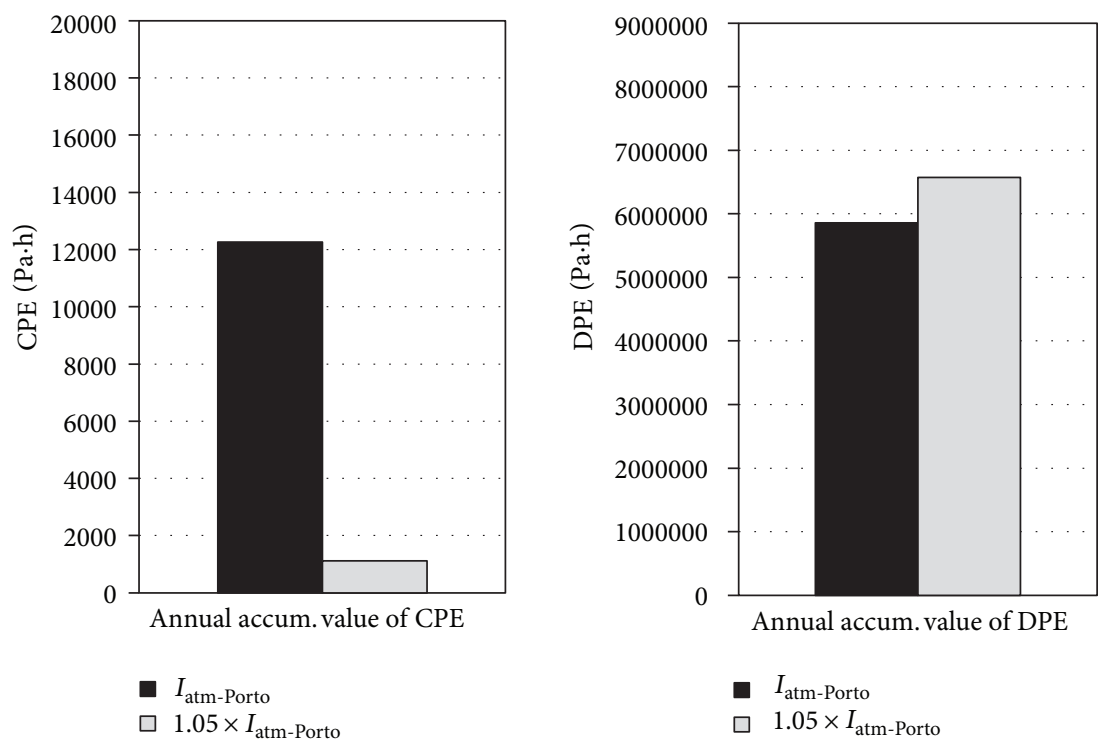

FIgURE 19: Exterior climate: atmospheric radiation.
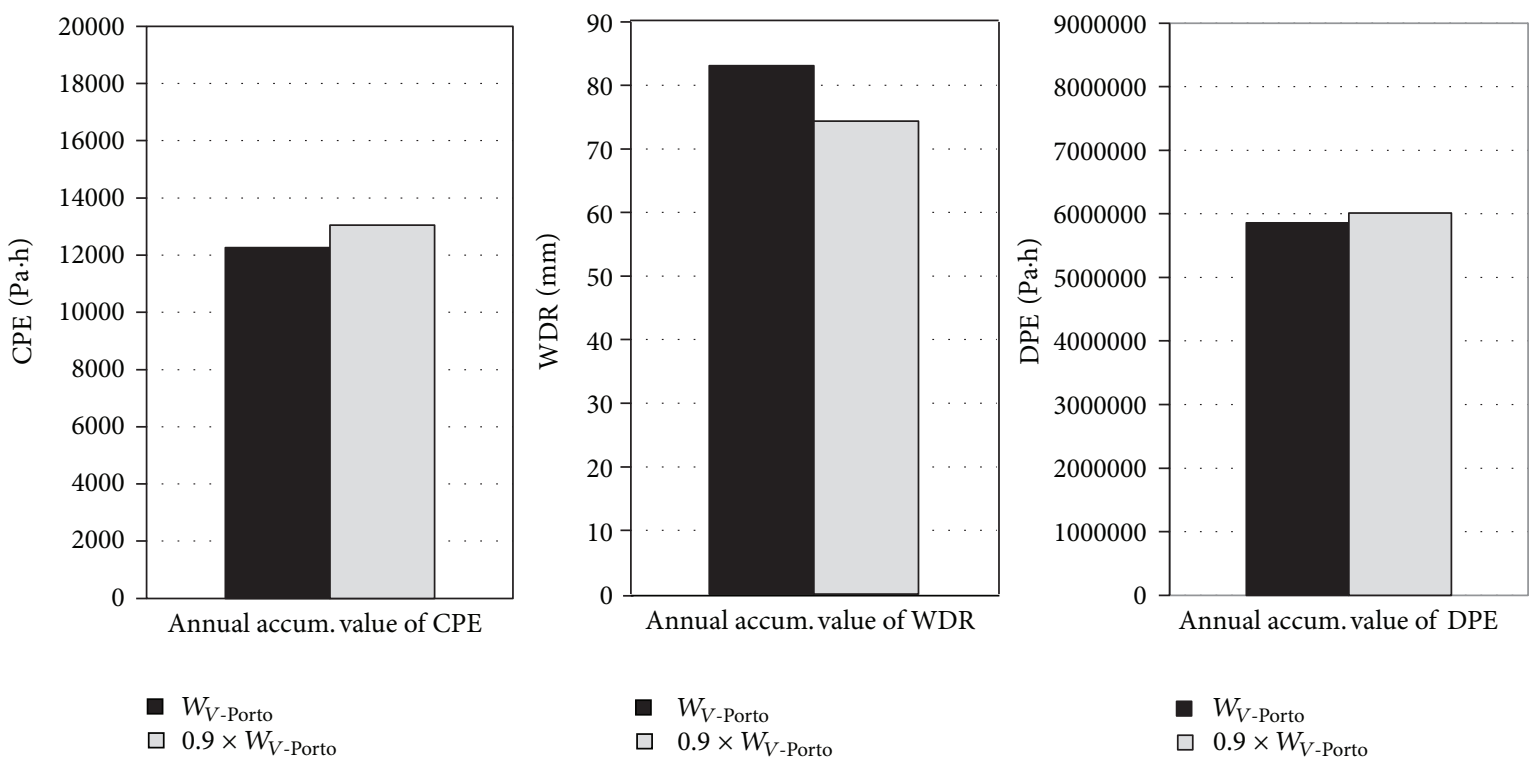

Figure 20: Exterior climate: wind velocity.

height of the building, wind velocity, wind direction, and orientation.

The climatic parameters, influencing surface wetting of ETICS, cannot be controlled by man. However, they may justify differential behaviour of a building façade due to the local climate.

(i) Local relative humidity, in a specific microclimate, may be higher due to the existence of, for example, a lake, a river, the sea, and so forth, which will increase the amount of water vapour in the air that is available to condensate and decrease the drying capacity of the surface.

(ii) The existence of other buildings nearby a façade covered with ETICS may be simulated by increasing the amount of the atmospheric radiation that reaches the façade, which is a climate parameter $[14,15]$. Therefore, nearby obstacles may change the radiative balance on the surface, by increasing the gains of longwave radiation during the night. In a façade nearby an obstacle surface condensation is less intense than in a more exposed surface due to the increase of exterior surface temperature during the night.

(iii) If a building is located in a valley or in a depression of the terrain, where local temperature of the exterior air changes about 1 or $2^{\circ} \mathrm{C}$, its façade may present different hygrothermal behaviour. If the temperature is higher, the amount of water vapour in the air that is available to condensate is also higher, which it is 

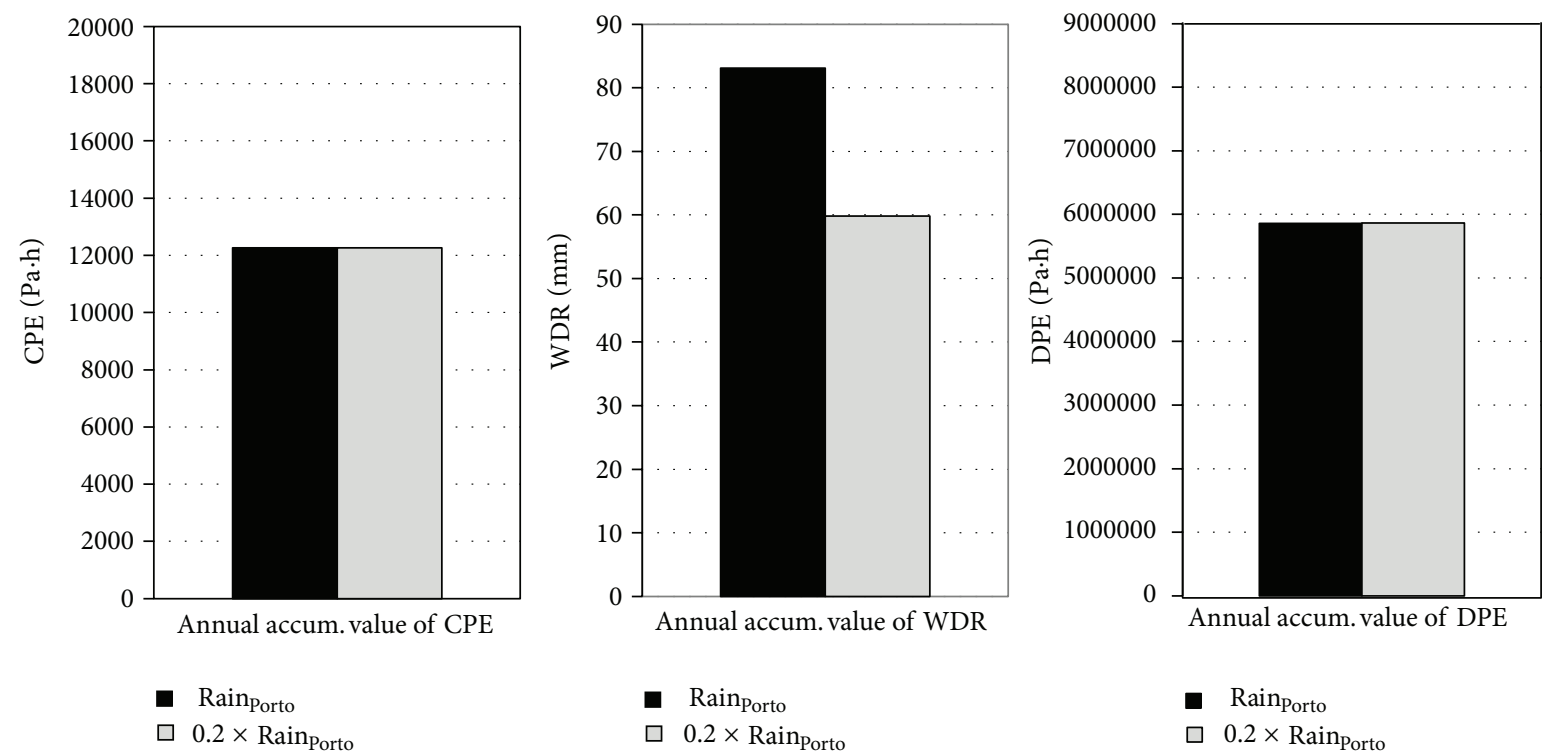

FIGURE 21: Exterior climate: rain.
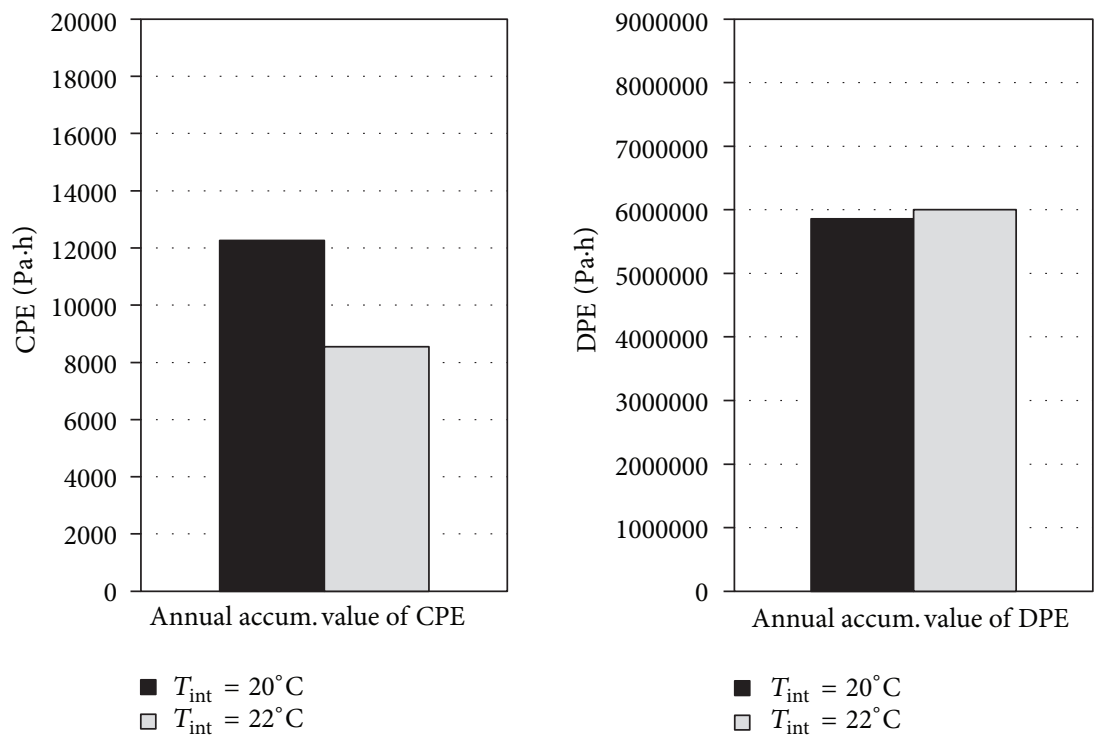

FIGURE 22: Interior climate: temperature.

not compensated by the small increase in the drying capacity.

(iv) Also rain and wind, although they do not influence much surface condensation, may have an important role in the surface wetting of ETICS as they are key parameters in the amount of rain water that reaches the façade. Buildings located in rainy and windy territories are more prone to wetting than buildings located in less exposed locations.

(v) Exposure to sunlight and to wind without rain may also affect the building hygrothermal behaviour as it influences the drying process. When a building is located, for example, in the top of a hill without any relevant obstacles that protect it from wind and shadow sunlight, its façades will probably present lower surface moisture content.

The way buildings are used may also influence exterior surface moisture content. If the interior is heated continuously during the winter, exterior surface condensation may be reduced as the heat flow by conduction coming from the interior slightly increases the exterior surface temperature.

Total thermal resistance of the façade has also an important role. Total thermal resistance depends mostly on the thickness of the thermal insulation layer that is calculated based on the country legislation in connection with the comfort level demanded by the users. However, designers must be aware that the thicker the insulation layer is, the higher 
the amount of surface condensation may be, because the heat flow by conduction coming from the interior decreases.

Although orientation is not a relevant parameter concerning surface condensation, it is quite important for wetting due to wind-driven rain (rain water only reaches the surface normal to the wind direction) and for the drying process (direct solar radiation on the surface varies considerably with orientation). That is the reason why exterior surface moisture content varies between different façades of the same building and the aesthetic impact due to biological growth is considerably different.

The exterior rendering properties are very relevant in ETICS exterior surface moisture content, namely, emissivity and absorbance to solar radiation. To decrease surface condensation, emissivity must be reduced. To improve the drying capacity, absorbance to solar radiation must be increased beneath certain limits that insure ETICS proper performance [34]. Moisture diffusivity that rules the transfer of liquid water through porous materials, although does not influence surface condensation, WDR, nor the drying process, has some impact on the availability of liquid water on the surface. Lower moisture diffusivity allows longer availability of liquid water on the surface as less water is absorbed by the plaster system following WDR and surface condensation [13]. Of course, it may also improve the potential drainage. Although the thermal and hygric properties of the exterior rendering are very similar for all ETICS available in the market, further studies in this field may allow achieving a better economical and environmental solution to ETICS hygrothermal behaviour.

\section{Conflict of Interests}

The authors declare that there is no conflict of interests regarding the publication of this paper.

\section{Acknowledgment}

The authors would like to thank the financial support of Fundação para a Ciência e Tecnologia (FCT) that allowed the necessary conditions to carry out this study (Doctoral Grant SFRH/BD/39904/2007).

\section{References}

[1] F. Fleury and B. Abraham, L'Isolation Thermique des Façades par L'Extérieur, CSTB, Paris, France, 1982.

[2] P. Baronnie, "Manuel de mise en oeuvre des enduits minces sur isolant. Isolation par l'extérieur. Le bon exemple de l'applicateur K'PLIC," CSTB, Paris, France, 1983.

[3] J. Blaich, La Détérioration des Bâtiments-Analyse et Prévention, EMPA, Dübendorf, Suisse, 1999.

[4] V. P. Freitas, "Isolamento térmico de fachadas pelo exterior. Reboco delgado armado sobre poliestireno expandidoETICS," Prof. Eng. Vasco Peixoto de Freitas, L.da-Relatório HT 191A/02. Portugal, 2002.

[5] H. Hens and J. Carmeliet, "Performance prediction for masonry walls with EIFS using calculation procedures and laboratory testing," Journal of Thermal Envelope and Building Science, vol. 25, no. 3, pp. 167-188, 2002.

[6] H. Kunzel, H. M. Kunzel, and K. Sedlbauer, "Long-term performance of external thermal insulation systems (ETICS)," Architectura, vol. 5, no. 1, pp. 11-24, 2006.

[7] H. Barberousse, R. Brayner, A. M. B. Do Rego, J.-C. Castaing, P. Beurdeley-Saudou, and J.-F. Colombet, "Adhesion of façade coating colonisers, as mediated by physico-chemical properties," Biofouling, vol. 23, no. 1, pp. 15-24, 2007.

[8] H. Barberousse, B. Ruota, C. Yéprémianb, and G. Boulonc, "An assessment of façade coatings against colonisation by aerial algae and cyanobacteria," Building and Environment, vol. 42, pp. 2555-2561, 2007.

[9] R. Becker, "Patterned staining of rendered facades: hygrothermal analysis as a means for diagnosis," Journal of Thermal Envelope and Building Science, vol. 26, no. 4, pp. 321-341, 2003.

[10] M. Krus, D. Rösler, and K. Sedlbauer, "New model for the hygrothermal calculation of condensate on the external building surface," in Proceedings of the 3rd International Building Physics Conference-Research in Building Physics and Building Engineering, pp. 329-333, August 2006.

[11] H. M. Kunzel and K. Sedlbauer, Biological Growth on Stucco. Performance of Exterior Envelopes of Whole Buildings VIII: Integration of Building Envelopes, ASHRAE, Florida, USA, 2001.

[12] K. Sedlbauer and M. Krus, "Mold growth on ETICS (EIFS) as a result of "bad workmanship"?" Journal of Thermal Envelope and Building Science, vol. 26, no. 2, pp. 117-121, 2002.

[13] H. Venzmer, J. Von Werder, N. Lesnych, and L. Koss, "Algal defacement of façade materials-results of long term natural weathering tests obtained by new diagnostic tools," in Proceedings of the 8th Symposium on Building Physics in the Nordic Countries, vol. 1, pp. 277-284, DTU, Copenhagen, Denmark, 2008.

[14] E. Barreira and V. P. Freitas, "The effect of nearby obstacles in surface condensations on external thermal insulation composite systems: experimental and numerical study," Journal of Building Physics, 2013.

[15] E. Barreira and V. P. Freitas, "Experimental study of the hygrothermal behaviour of External Thermal Insulation Composite Systems (ETICS)," Building and Environment, vol. 63, pp. 31-39, 2013.

[16] European Organization for Technical Approvals-Eota, "Guideline for European technical approval of external thermal insulation composite systems with rendering-ETAG 004," EOTA, Belgium, 2000.

[17] Qualité Construction-Agence Pour la Prévention des Désordres et L'Amélioration de la Qualité de la Construction (n.d.), "L'isolation thermique par l'exterieur-Enduit mince sur isolant," Agence Qualité Construction, France.

[18] J. M. P. Q. Delgado, N. M. M. Ramos, E. Barreira, and V. P. De Freitas, "A critical review of hygrothermal models used in porous building materials," Journal of Porous Media, vol. 13, no. 3, pp. 221-234, 2010.

[19] H. Kunzel, Simultaneous Heat and Moisture Transport in Building Components-One and Two-Dimensional Calculation Using Simple Parameters, IRB, Stuttgart, Germany, 1995.

[20] WUFI, WUFI Pro 5, Fraunhofer-IBP, Holzhirchen, Germany, 2009.

[21] M. Kehrer and T. Schmidt, "Radiation effects on exterior surfaces," in Proceedings of the 8th Symposium on Building Physics in the Nordic Countries, vol. 1, pp. 207-212, DTU, Copenhagen, Denmark, 2008. 
[22] M. Martin and P. Berdahl, "Characteristics of infrared sky radiation in the United States," Solar Energy, vol. 33, no. 3-4, pp. 321-336, 1984.

[23] C. Finkenstein and P. Haupl, "Atmospheric long wave radiation being a climatic boundary condition in hygrothermal building part simulation," in Proceedings of the 12th Symposium for Building Physics, vol. 2, pp. 617-624, Technische Universitat Dresden, Dresden, Germany, 2007.

[24] Meteotest, "Meteonorm-Version 6.0.," Meteotest, Bern, Switzerland, 2007.

[25] E. Barreira, Degradação biológica de fachadas com sistemas de isolamento térmico pelo exterior devida ao desempenho higrotérmico [Ph.D. thesis], FEUP, Porto, Portugal, 2010.

[26] K. Nore, B. Blocken, B. Petter Jelle, J. V. Thue, and J. Carmeliet, "A dataset of wind-driven rain measurements on a low-rise test building in Norway," Building and Environment, vol. 42, no. 5, pp. 2150-2165, 2007.

[27] A. Holm, W. Zillig, and H. Kunzel, "Exterior surface temperature and humidity of walls-comparison of experiment and numerical simulation," in Proceedings of the Performance of Exterior Envelopes of Whole Buildings IX, ASHRAE, Fla, USA, 2004.

[28] C.-E. Hagentoft, Introduction to Building Physics, Studentlitteratur, Sweden, 2001.

[29] R. Zheng, A. Janssens, J. Carmeliet, W. Bogaerts, and H. Hens, "An evaluation of highly insulated cold zinc roofs in a moderate humid region-part I: hygrothermal performance," Construction and Building Materials, vol. 18, no. 1, pp. 49-59, 2004.

[30] W. Zillig, K. Lenz, and M. Krus, "Condensation on façadesinfluence of construction type and orientation," in Research in Building Physics, pp. 437-444, K. U. Leuven, Leuven, Belgium, 2003.

[31] M. Krus, C. Fitz, and A. Holm, "Prevention of algae and mould growth on facades by coatings with lowered longwave emission," in Proceedings of the 3rd International Building Physics Conference-Research in Building Physics and Building Engineering, pp. 973-978, August 2006.

[32] S. S. Freitas, E. Barreira, and V. P. Freitas, "Quantification of wind-driven rain and evaluation of façade humidification," in Proceedings of the 2nd Central European Symposium on Building Physics, pp. 775-782, Vienna University of Technology, Vienna, Austria, 2013.

[33] H. Hens, Building Physics-Heat, Air and Moisture. Fundamentals and Engineering Methods with Examples and Exercises, Ernst \& Sohn-Wiley, Leuven, Belgium, 2007.

[34] Centre Scientifique et Technique du Batiment-CSTB, "Systèmes d'isolation thermique extérieure avec enduit mince sur polystyrène expansé-cahier des prescriptions techniques d'emploi et de mise en oeuvre," Cahier du CSTB 3035. CSTB, Paris, France, 1998. 

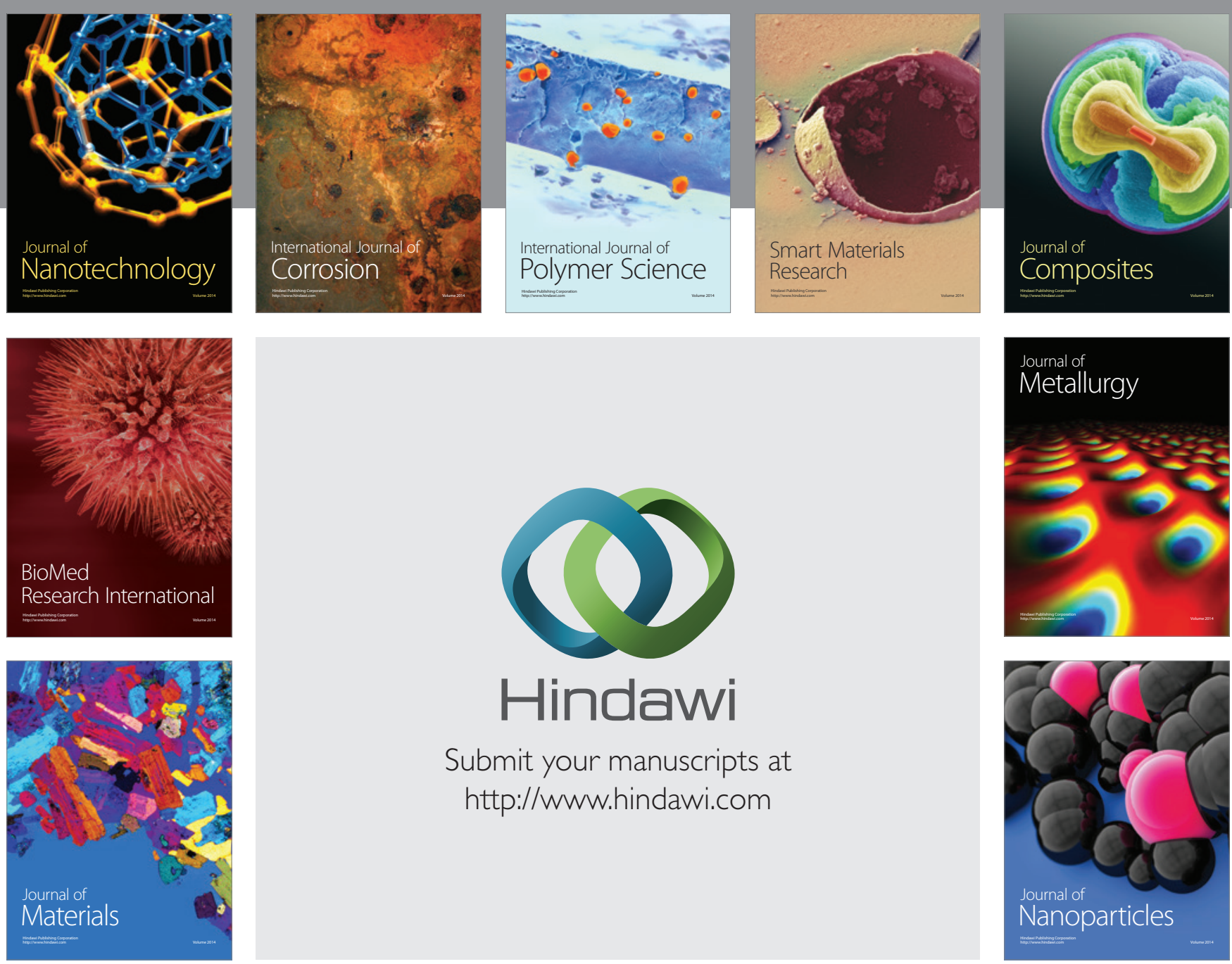

Submit your manuscripts at http://www.hindawi.com
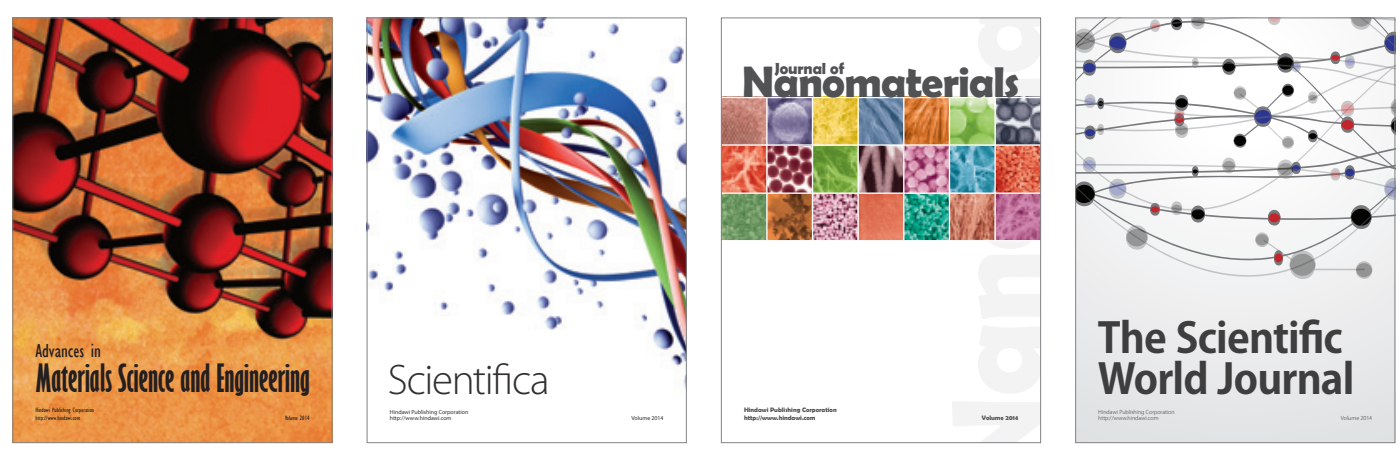

\section{The Scientific World Journal}
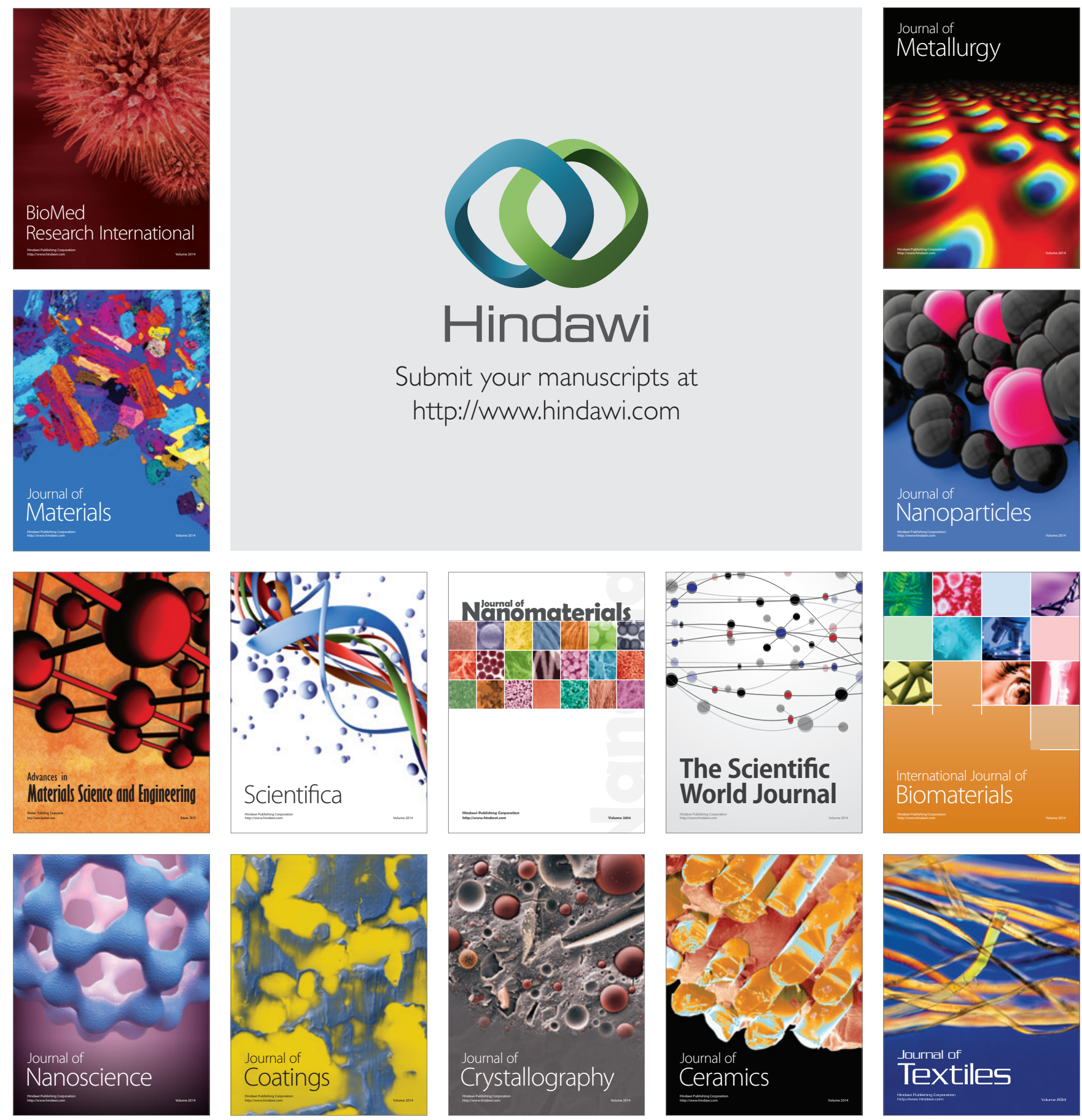